\title{
Integrating transcriptomics and proteomics to show that tanshinone IIA suppresses cell growth by blocking glucose metabolism in gastric cancer cells
}

\author{
Li-Ling Lin ${ }^{1}$, Chieh-Ren Hsia ${ }^{1}$, Chia-Lang Hsu' ${ }^{1}$ Hsuan-Cheng Huang ${ }^{2 *}$ and Hsueh-Fen Juan 1,3,4*
}

\begin{abstract}
Background: Tanshinone IIA (TIIA) is a diterpene quinone extracted from the plant Danshen (Salvia miltiorrhiza) used in traditional Chinese herbal medicine. It has been reported to have anti-tumor potential against several kinds of cancer, including gastric cancer. In most solid tumors, a metabolic switch to glucose is a hallmark of cancer cells, which do this to provide nutrients for cell proliferation. However, the mechanism associated with glucose metabolism by which TIIA acts on gastric cancer cells remains to be elucidated.
\end{abstract}

Results: We found that TIIA treatment is able to significantly inhibit cell growth and the proliferation of gastric cancer in a dose-dependent manner. Using next-generation sequencing-based RNA-seq transcriptomics and quantitative proteomics-isobaric tags for relative and absolute quantification (iTRAQ), we characterized the mechanism of TIIA regulation in gastric cancer cell line AGS. In total, 16,603 unique transcripts and 102 proteins were identified. After enrichment analysis, we found that TIIA regulated genes are involved in carbohydrate metabolism, the cell cycle, apoptosis, DNA damage and cytoskeleton reorganization. Our proteomics data revealed the downregulation of intracellular ATP levels, glucose-6-phosphate isomerase and L-lactate dehydrogenase B chains by TIIA, which might work with disorders of glucose metabolism and extracellular lactate levels to suppress cell proliferation. The up-regulation of p53 and down-regulation of AKT was shown in TIIA-treated cells, which indicates the transformation of oncogenes. Severe DNA damage, cell cycle arrest at the $\mathrm{G}_{2} / \mathrm{M}$ transition and apoptosis with cytoskeleton reorganization were detected in TIIA-treated gastric cancer cells.

Conclusions: Combining transcriptomics and proteomics results, we propose that TIIA treatment could lead cell stresses, including nutrient deficiency and DNA damage, by inhibiting the glucose metabolism of cancer cells. This study provides an insight into how the TIIA regulatory metabolism in gastric cancer cells suppresses cell growth, and may help improve the development of cancer therapy.

Keywords: Tanshinone IIA, Gastric cancer, Glycolysis, Isobaric tags for relative and absolute quantification, Next generation sequencing

\section{Background}

Gastric cancer is one of the most notorious cancers worldwide. It is the fourth most frequently occurring cancer, and the second most common cause of death for both sexes among all cancers, claiming over 736,000 lives

\footnotetext{
* Correspondence: hsuancheng@ym.edu.tw; yukijuan@ntu.edu.tw

${ }^{2}$ Institute of Biomedical Informatics and Center for Systems and Synthetic

Biology, National Yang-Ming University, No.155, Sec.2, Linong Street, Taipei

112, Taiwan

${ }^{1}$ Department of Life Science, National Taiwan University, No. 1, Sec. 4,

Roosevelt Road, Taipei 106, Taiwan

Full list of author information is available at the end of the article
}

worldwide in 2008 [1]. However, anti-cancer drug development of gastric cancer today remains slow and costly, and drug-resistance remains a potential obstacle [2].

Tanshinone IIA (TIIA) is a diterpene quinone extracted from the plant Danshen (Salvia miltiorrhiza), which is used in traditional Chinese medicine [3]. The first usage of Danshen extractions as herbal medicine can be traced back to more than 1800 years ago [4]. Its applications include prevention of cardiac diseases [5], protection of the nervous system [6] and hepatocytes [7], and inhibition of osteoporosis [8]. Drug repositioning is considered to be a promising and valuable method for the reduction of the 
side effects and cost of anti-cancer drug research and development. The functions of many chemicals extracted from Danshen are therefore explored for their anti-cancer potential, and TIIA is the most abundant and structurally representative of these [9]. TIIA has been recently reported to have anti-cancer potential against several cancers including breast cancer [10], prostate cancer [11], colorectal cancer [12], lung cancer [13], liver cancer [14], leukemia [15], and gastric cancer [16]. However, the regulatory mechanism of TIIA in gastric cancer cells remains unclear.

Metabolic transformation accompanying nutritional imbalance is one of the leading causes of cancer progression. Glucose is a primary source for the pentose phosphate pathway, which makes RNA and DNA. Glycolytic intermediates can be used to assist lipid biosynthesis to produce ATP and non-essential amino acids, such as alanine, for growth [17]. Proliferating cells are commonly maintained by enhancing aerobic glycolysis, also called the Warburg effect, which causes lactate accumulation and contributes to the development of malignancies. In oncogenic pathways, phosphatidylinositide 3-kinases (PI3K)/ protein kinase B (AKT) has been shown to enhance glycolysis, while the tumor suppressor p53 inhibits it, suggesting a glycolytic switch intrinsically associated with oncogenic transformation [18]. Through the inference of oncogene expression and glucose metabolism, the supply of nutrients to cancer cells could be blocked, which would stunt their proliferative potential. This may be an important finding for drug discovery.

High-throughput data can be used to provide a comprehensive inventory of all the biological processes of cells, display their complexity, and increase data accuracy. An accurate picture of the differential expression of experimental samples is important for defining precise targets and networks. Here we use two types of highthroughput data to uncover the regulatory mechanism of TIIA in gastric cancer cells: transcription levels from next-generation sequencing (NGS) data, and isobaric tags for relative and absolute quantification (iTRAQ)based quantitative proteomics analysis. NGS is one of newer transcriptome sequencing approaches and can perform high-throughput sequencing by generating thousands or millions of sequences in parallel [19]. It has better sensitivity and lower background noise than microarray analysis, and more researchers are using it to investigate the mechanisms of anti-cancer drugs $[19,20]$. iTRAQ is a promising new technique for quantitative proteomics which can quantify proteins from different sources using their different tags [21]. Because of its sensitivity in labeling peptides, it is considered a more powerful quantitative proteomic technique than others, including the two frequently used quantitative proteomics techniques 2D-DIGE (difference gel electrophoresis) and cICAT (cleavable isotope-coded affinity tags) [22,23].

In this study, we identified a total of 16,603 unique transcripts and 102 TIIA-regulated proteins that are involved in glucose metabolic process. We further investigated and found that TIIA blocks glycolysis and gluconeogenesis in cancer cells by altering protein expression, and causes DNA damage, cell cycle arrest, cytoskeleton reorganization and apoptosis.

\section{Results}

TIIA reduces the growth rate and suppresses proliferation of gastric cancer AGS cells

To determine whether TIIA can affect gastric cancer cell survival, we treated AGS cells with different concentrations to detect real-time cell growth rates by an RTCA (Real-Time Cell Analyzer; xCELLigence ${ }^{\mathrm{Tx}}$; Roche Applied Science \& ACEA Biosciences) system. The $\mathrm{IC}_{50}$ of TIIA at $48 \mathrm{hr}$ was calculated to be $5.3 \mu \mathrm{M}$. Figure 1A shows that $0.1 \mu \mathrm{M}$ TIIA was only slightly effective, whereas $10 \mu \mathrm{M}$ TIIA killed almost all cells. Each curve is significantly different from the other $(p<0.0001$, Wilcoxon Signed-Rank Test). Our results demonstrate that the cell growth rate was significantly decreased under TIIA treatment conditions compared with controls, suggesting that AGS cell growth was significantly inhibited by TIIA in a dose-dependent manner.

To explore whether TIIA could affect gastric cancer cell proliferation rates, we treated AGS cells at different concentrations of TIIA and counted the number of cell colonies stained with crystal violet. The results show that $0.53 \mu \mathrm{M}\left(1 / 10 \quad \mathrm{IC}_{50}\right)$ TIIA reduces colonies to about $60 \%$, whereas $5.3 \mu \mathrm{M}\left(\mathrm{IC}_{50}\right)$ TIIA results in almost no colonies. It indicates that the proliferation rate of AGS cells was significantly suppressed by TIIA in a dosedependent manner $\left(" p<0.05,{ }^{* *} p<0.01\right.$, Student's $t$-test) (Figure $1 \mathrm{~B}$ and $\mathrm{C}$ ).

\section{Functional annotation enrichment of TIIA -regulated genes}

To uncover the TIIA regulatory mechanism in AGS cells, we performed RNA-seq analysis to profile the transcriptomes of gastric cancer cells when treated with dimethyl sulfoxide (DMSO) (control) or with TIIA. In order to characterize the gene expression profile to response of biological functions, our initial analysis performed functional enrichment of all identified genes onto MetaCore pathway analysis. Major bio-functional networks were significantly enriched and showed in Figure 2A. Of six bio-functional networks, "Catabolic process" is top-ranked. Previous studies have shown that dysregulation of metabolism is an important indicator for tumorgenesis [17]. Thus, we forced on metabolic networks to enrich all identified genes by MetaCore. As indicated in Figure 2B, a large number of glucose networks were affected, including 


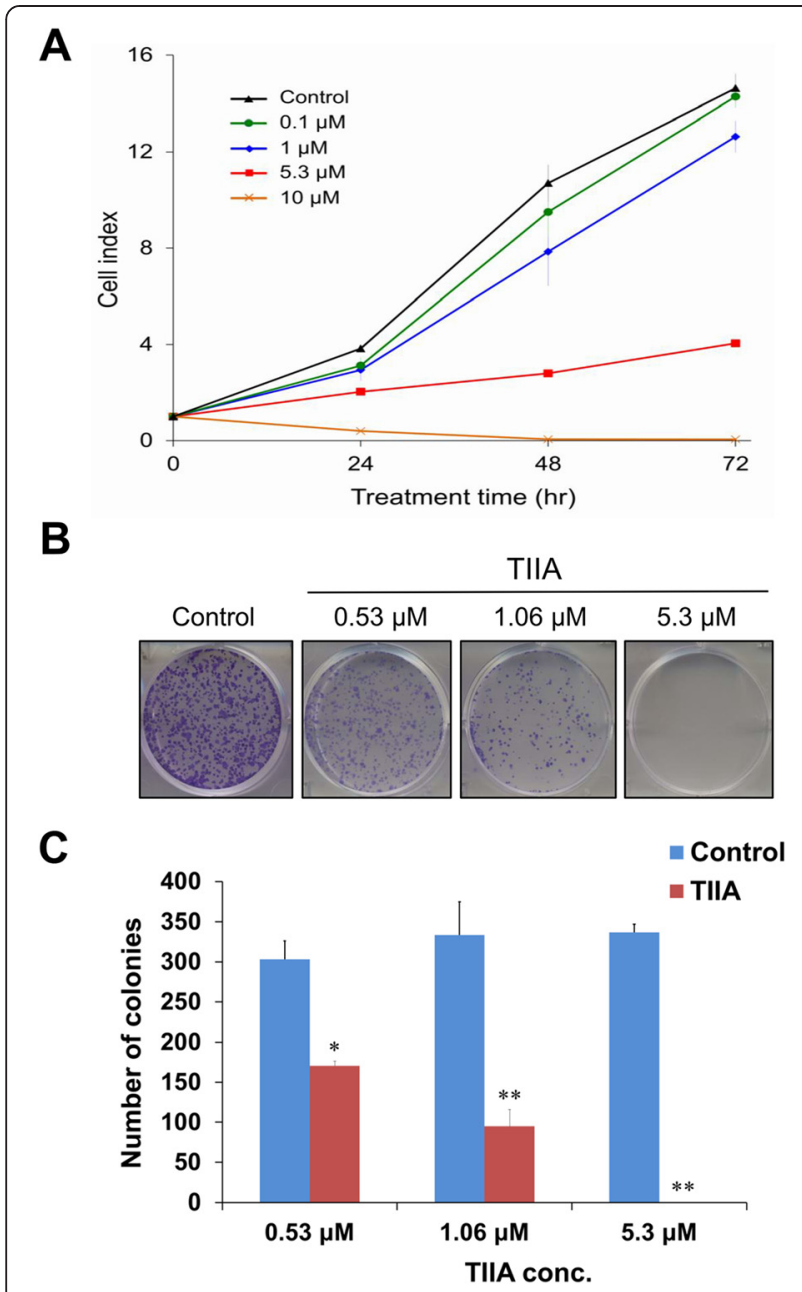

Figure 1 Effects of TIIA on cell growth and proliferation of AGS cells. (A) Growth curves show a dosage-dependent pattern of growth inhibition after TIIA treatment for $72 \mathrm{hr}$. All TIIA treatment conditions had significant effects on AGS cell growth $(p<0.0001$, Wilcoxon Signed-Rank Test). Cell indexes of AGS cells were measured by an RTCA DP ${ }^{\oplus}$ system, expressed as mean \pm SD of three replications. (B) Colonies of AGS cells were stained by crystal violet (purple-colored dots) after TIIA treatment. Control conditions exhibit many colonies, while $\mathrm{IC}_{50} \mathrm{TIIA}$ conditions have produced almost no colonies. (C) TIIA significantly reduces the number of AGS colonies $\left({ }^{*} p<0.05\right.$, ${ }^{* *} p<0.01$, Student's $t$-Test) in a dosage-dependent manner. Histogram values are expressed as mean \pm SD from three replications.

Phosphatidylinositol-4,5-diphosphate pathway, Phosphatidylinositol-3,4,5-triphosphate pathway, Ceramide pathway, Pentose phosphate pathways and transport, Glucose pathway, Glycolysis, Gluconeogenesis and glucose transport, and Sucrose metabolism and transport. It has been known that PI3K, an key enzyme of phosphatidylinositol4,5-diphosphate and phosphatidylinositol-3,4,5-triphosphate pathways, increases glycolysis in cancer cells [18]. Based on these results, we propose that TIIA-regulated pathways involving in the enriched Glycolysis, Gluconeogenesis and glucose transport network (Figure 2C).
Moreover, a total of 2,761 differentially expressed genes (DEGs) were considered that have different expression between control and TIIA treatment samples (FDR $\leq 0.001$ and $\mid \log _{2}$ (fold-change) $\mid \geq 1$ ) (Additional files 1 and 2). Among these, 1,010 genes were up-regulated and 1,751 genes were down-regulated by TIIA. MetaCore networks analysis of DEGs reveals significantly enriched biological processes that frequently occur in gastric cancer cells with TIIA treatment. As shown in Table 1 and Additional file 3, major bio-functional networks were in correspondence with the enrichment analysis of integrative transcriptome (Figure 2A), such as Cell cycle_G2-M, DNA damage_DBS repair, Apoptotic nucleus, Cytoskeleton_Intermediate filaments.

Proteomic expression profiling of TIIA-treated gastric cells To further elucidate cellular mechanism and molecular function, we performed iTRAQ-based proteomics analysis to assess the protein expression profiles in AGS cells with TIIA treatment. Equal amounts of peptides collected from control samples or TIIA-treated samples were labeled with iTRAQ reagents, respectively, and used for replication (control samples labeled by 114 or 115; TIIA-treated samples labeled by 116 or 117). All labeled peptides were mixed and analyzed by liquid chromatography coupled with tandem mass spectrometry (LC-MS/MS). A total of 102 differentially expressed proteins were identified with a false discovery rate (FDR) of 3.94\%; annotated MS/MS spectra are collected in Table 2 and Additional file 4. There were $100 \%$ of identified peptides that were labeled with iTRAQ reagents. The intensity levels of iTRAQ signals distribution plots show that positive correlation among our treatments (Additional file 5), suggesting that labeled samples with a high reproducibility were present in this study.

In order to validate iTRAQ data, we evaluated certain identified protein expression patterns (fold change $>1.5$ or $<0.65$ ) by Western blot analysis, including proteasome subunit $\beta$ type-3 (PSMB3), 40S ribosomal protein S2 (RS2) and glucose-6-phosphate isomerase (G6PI). In our MS/MS spectra, PSMB3 (Figure 3A), RS2 (Figure 3B) and G6PI (Figure 3C) displayed a high intensity across different samples. After western blotting analysis, PSMB3 can be detected to be significantly up-regulated (fold change $=1.45, p<0.05$ ) whereas RS2 (fold change $=0.49$, $p<0.01$ ) and G6PI (fold change $=0.1, p<0.01$ ) were significantly down-regulated (Figure 3D). As our results, expression patterns of PSMB3, RS2 and G6PI correspond with our iTRAQ data for those proteins, suggesting the consistence between iTRAQ and western blotting data.

\section{TIIA suppresses glucose metabolism of gastric cancer cells}

To delineate the mechanism of TIIA in gastric cancer cells, we compared our quantitative proteomics and transcriptomics 


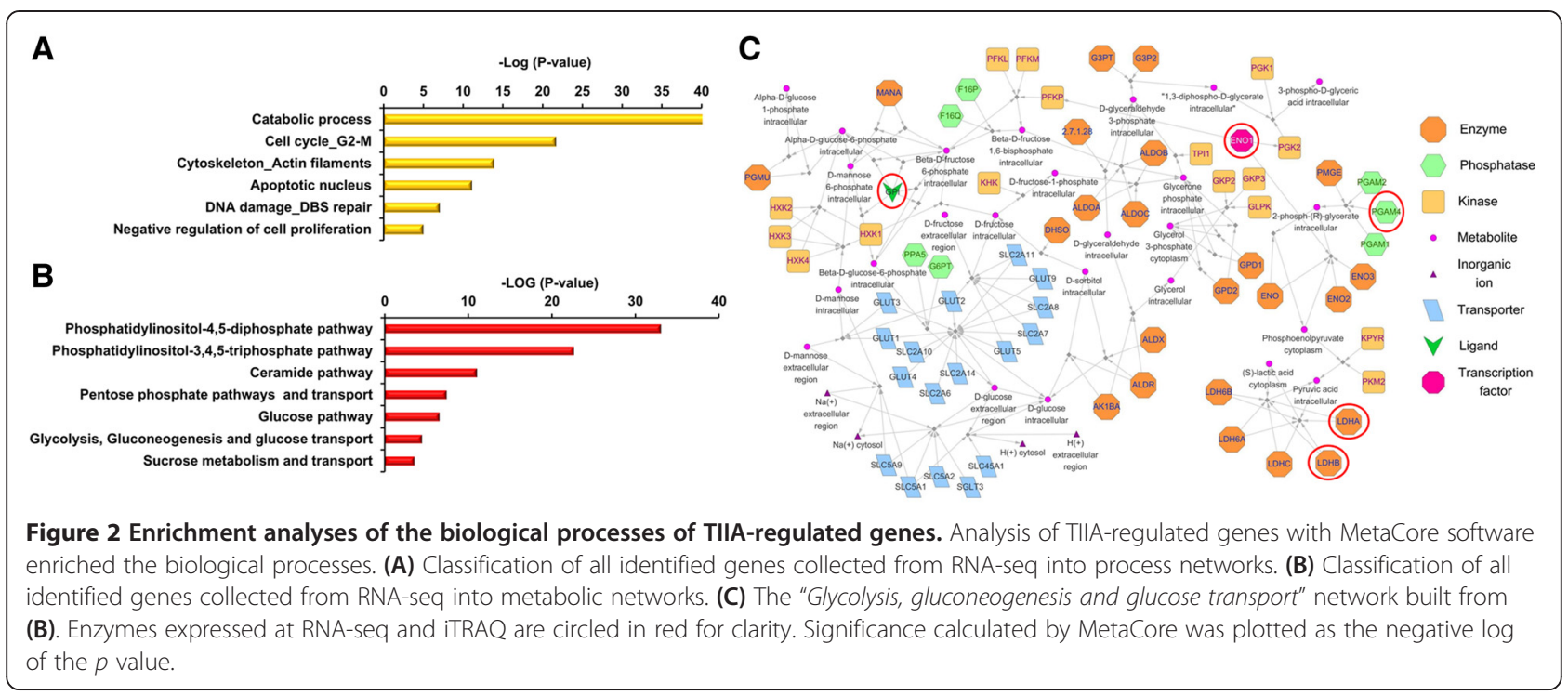

data. We found TIIA regulated not only genes but also proteins involved in glycolysis, the cell cycle, apoptosis, DNA damage and cytoskeleton rearrangement. As shown in Figure 2C, five proteins (PGAM4, ENO1, LDHA, LDHB and G6PI) were identified at both the protein and transcription level. After western blotting analysis, we found that the protein expression of G6PI and LDHB was downregulated by TIIA, and ENO1 was not changed (Figures 3D and 4A). Because G6PI and LDHB are important enzymes in glycolysis and gluconeogenesis, respectively, we further examined if TIIA can regulate other proteins related to glucose metabolism, such as aldolase C (ALDOC), malate dehydrogenase 1 (MDH1), phosphoenolpyruvate carboxykinase 2 (PCK2) and phosphoglycerate kinase 1 (PGK1), which are involved in gluconeogenesis. ALDOC and PCK2 were also identified in our transcriptomics data (Additional file 2). MDH1, which reduces oxaloacetate to malate in the mitochondria, was downregulated by TIIA. PCK2, which converts oxaloacetate to phosphoenolpyruvate, was up-regulated by TIIA (Figure 4B). The transformation of oncogenes, such as p53 and $\mathrm{AKT}$, is also involved in the glucose metabolism switch in cancer cells [18]. We found that p53 increased and AKT decreased in gastric cancer cells following TIIA treatment (Figure 4C). Additionally, TIIA treatment significantly decreased the intracellular ATP

Table 1 Enrichment analysis of RNA-seq-identified DEGs by MetaCore software

\begin{tabular}{|c|c|c|}
\hline $\begin{array}{l}\text { Function description } \\
\text { (number of genes) }\end{array}$ & $P$-value & Differentially expressed genes (DEGs) \\
\hline Cell cycle_G2-M (75) & $9.611 \mathrm{E}-13$ & $\begin{array}{l}\text { Cyclin G, DNMT3B, Ubiquitin, TOP2 beta, ANAPC4, Condensin, UBC, Brca1, Cyclin B, PDGF-B, Cyclin B2, Brca2, } \\
\text { Histone H3, HUS1, Miz-1, CDC25C, PTCH1, TRF1, Cyclin A2, BLM, CAP-G, PLK4 (STK18), FANCD2, CAP-G/G2, } \\
\text { 14-3-3 sigma, EGFR, GTSE1, ATM, MAD2a, FOXM1, Lamin B1, GADD45 beta, 14-3-3, BUBR1, TOP2 alpha, CAP-H/H2, } \\
\text { PDGF-A, LATS2, Lamin B, ETS2, GADD45 alpha, CAP-C, Cyclin A, CNAP1, Rad50, Cyclin G2, DNMT1, Skp2/TrCP/FBXW, } \\
\text { CAP-D2/D3, KNSL1, Aurora-B, CDC25A, SKP2, DNMT3A, TOP2, PDGF-R-alpha, Dynamin, p21, BUB1, BRRN1, PDGF } \\
\text { receptor, ATR, Cyclin B1, Emi1, C-Myc, Claspin, Aurora-A, CDC25, ATRIP, PKA-cat (cAMP-dependent), CAP-E, } \\
\text { Histone H1, CDK1 (p34), CDK7, CDC27 }\end{array}$ \\
\hline
\end{tabular}

DNA damage_DBS repair (44)

Apoptosis_Apoptotic nucleus (49)

Cytoskeleton_Intermediate 4.660E-06 filaments (30)
1.260E-08 Ubiquitin, TOP2 beta, Tip60, Sirtuin, MRE11, Brca1, BRIP1, Brca2, MeCP2, Histone H3, MRN complex, C1D, HMGB1, BLM, FANCD2, RAD54B, RAD54L, SMC6, ATM, DNA ligase IV, DNA-PK, NEK1, TOP2 alpha, FANCA, Histone H2AX, SMC5, PP2A regulatory, Rad50, ChAF1 subunit B, XRCC2, FANCL, TOP2, Sirtuin6, ATR, PSF, DNA polymerase eta, FANCM, PIR51, Nibrin, HMG1,2, WRN, ATRIP, Histone H4, p53BP1

3.077E-06 Tip60, NRIF3, NF-kB2 (p100), DNA polymerase kappa, RelA (p65 NF-kB subunit), Brca1, PARP-1, Tubulin alpha, TIA-1, Separase, Histone H3, ROCK2, Caspase-6, BLM, FANCD2, iASPP, C/EBPbeta, Granzyme B, IEX1, ATM, Histone H2B, IRF5, DOCK1, DNA ligase IV, FOXO3A, DNA-PK, c-Myb, c-Jun, Protein p8, Lamin B1, GADD45 beta, Clusterin, DFF40 (CAD), PHAP1 (pp32), Lamin B, UBE1C, GADD45 alpha, Axin1, NF-kB, p21, ATR, P53DINP1a, Bcl-6, Bard1, APP-BP1, Nibrin, XPD, Perforin, Histone H1

Plectin 1, Tubulin beta, Keratin 17, BPAG2, Desmin, PPL(periplakin), ROCK, Tubulin alpha, SYNE2, ROCK2, Keratin 18, Keratin 19, Keratin 8/18, Lamin B1, 14-3-3, Lamin B, Keratin 8, Nestin, Keratin 6A, BPAG1, TMPOA, TMPOB, Kinesin light chain, Plakophilin 2, Actin, Fimbrin, Peripherin, CDK1 (p34), Tubulin (in microtubules), Nesprin 1 
Table 2 List of iTRAQ-identified proteins regulated by TIIA

\begin{tabular}{|c|c|c|c|c|c|c|c|c|c|}
\hline No. & Biological function & Accession & Protein name & $\begin{array}{l}\text { Gene } \\
\text { symbol }\end{array}$ & $\begin{array}{l}\text { Protein } \\
\text { score }\end{array}$ & $\begin{array}{l}\text { No. of } \\
\text { quantified } \\
\text { peptides }\end{array}$ & $\begin{array}{l}\text { Coverage } \\
\text { (\%) }\end{array}$ & $\begin{array}{l}\text { iTRAQ } \\
\text { ratio }\end{array}$ & $\begin{array}{l}\text { RNA-Seq } \\
\text { ratio }\end{array}$ \\
\hline 1 & Glycolysis & P11166 & $\begin{array}{l}\text { Solute carrier family } 2 \text {, facilitated } \\
\text { glucose transporter member } 1\end{array}$ & SLC2A1 & 72 & 2 & 3 & 1.273 & 1.573 \\
\hline 2 & Glycolysis & Q8N0Y7 & $\begin{array}{l}\text { Probable phosphoglycerate } \\
\text { mutase } 4\end{array}$ & PGAM4 & 40 & 1 & 5.5 & 1.057 & 0.309 \\
\hline 3 & Glycolysis & P06733 & Alpha-enolase & ENO1 & 720 & 15 & 46.8 & 0.947 & 0.754 \\
\hline 4 & Glycolysis & P00338 & L-lactate dehydrogenase A chain & LDHA & 283 & 6 & 29.2 & 0.901 & 0.352 \\
\hline 5 & Glycolysis & P04406 & $\begin{array}{l}\text { Glyceraldehyde-3-phosphate } \\
\text { dehydrogenase }\end{array}$ & GAPDH & 813 & 14 & 55.2 & 0.823 & 0.934 \\
\hline 6 & Glycolysis & P07195 & L-lactate dehydrogenase B chain & LDHB & 274 & 9 & 29 & 0.736 & 0.553 \\
\hline 7 & Glycolysis & 060701 & UDP-glucose 6-dehydrogenase & UGDH & 49 & 1 & 4.3 & 1.001 & 1.938 \\
\hline 8 & Glycolysis & P06744 & Glucose-6-phosphate isomerase & GPI & 83 & 1 & 7.3 & 0.525 & 0.824 \\
\hline 9 & ATP metabolic process & P55072 & $\begin{array}{l}\text { Transitional endoplasmic } \\
\text { reticulum ATPase }\end{array}$ & VCP & 129 & 4 & 7.3 & 0.888 & 0.661 \\
\hline 10 & ATP metabolic process & P04075 & Fructose-bisphosphate aldolase A & ALDOA & 196 & 5 & 30.5 & 0.804 & 1.284 \\
\hline 11 & Protein folding & P14625 & Endoplasmin & HSP90B1 & 67 & 1 & 8.7 & 1.685 & 0.738 \\
\hline 12 & Protein folding & P60709 & Actin, cytoplasmic 1 & ACTB & 1161 & 30 & 47.2 & 1.129 & 0.795 \\
\hline 13 & Protein folding & P62937 & $\begin{array}{l}\text { Peptidyl-prolyl cis-trans } \\
\text { isomerase A }\end{array}$ & PPIA & 242 & 6 & 42.4 & 1.050 & 0.640 \\
\hline 14 & Protein folding & P23284 & $\begin{array}{l}\text { Peptidyl-prolyl cis-trans } \\
\text { isomerase B }\end{array}$ & PPIB & 69 & 2 & 11.6 & 1.084 & 0.988 \\
\hline 15 & Protein folding & P10809 & $\begin{array}{l}60 \mathrm{kDa} \text { heat shock protein, } \\
\text { mitochondrial }\end{array}$ & HSPD1 & 522 & 7 & 21.6 & 1.011 & 0.724 \\
\hline 16 & Protein folding & P07900 & Heat shock protein HSP 90-alpha & HSP90AA1 & 614 & 7 & 27.7 & 0.991 & 0.572 \\
\hline 17 & Protein folding & P38646 & Stress-70 protein, mitochondrial & HSPA9 & 71 & 1 & 4.1 & 1.037 & 0.946 \\
\hline 18 & Protein folding & P11142 & $\begin{array}{l}\text { Heat shock cognate } 71 \mathrm{kDa} \\
\text { protein }\end{array}$ & HSPA8 & 728 & 18 & 43.7 & 0.898 & 0.804 \\
\hline 19 & Protein folding & P50991 & $\begin{array}{l}\text { T-complex protein } 1 \text { subunit } \\
\text { delta }\end{array}$ & CCT4 & 55 & 1 & 4.5 & 0.890 & 0.883 \\
\hline 20 & Protein folding & P49368 & $\begin{array}{l}\text { T-complex protein } 1 \text { subunit } \\
\text { gamma }\end{array}$ & ССТ3 & 56 & 1 & 4.8 & 1.119 & 0.876 \\
\hline 21 & Protein folding & P50454 & Serpin $\mathrm{H} 1$ & SERPINH1 & 43 & 1 & 7.9 & 0.870 & 0.568 \\
\hline 22 & Protein folding & Q99832 & T-complex protein 1 subunit eta & ССT7 & 38 & 1 & 7.7 & 0.896 & 0.812 \\
\hline 23 & Protein folding & Q15084 & Protein disulfide-isomerase A6 & PDIA6 & 44 & 1 & 3.4 & 0.910 & 0.876 \\
\hline 24 & Protein folding & P08238 & Heat shock protein HSP 90-beta & HSP90AB1 & 549 & 5 & 32.6 & 0.783 & 0.738 \\
\hline 25 & DNA damage response & Q96QE3 & $\begin{array}{l}\text { ATPase family AAA } \\
\text { domain-containing protein }\end{array}$ & ATAD5 & 44 & 1 & 3.4 & 2.004 & 0.307 \\
\hline 26 & DNA damage response & P49720 & Proteasome subunit beta type- 3 & PSMB3 & 105 & 1 & 8.8 & 1.799 & 0.765 \\
\hline 27 & DNA damage response & P62979 & $\begin{array}{l}\text { Ubiquitin-40S ribosomal } \\
\text { protein } \text { S27a }\end{array}$ & RS27A & 46 & 1 & 21.2 & 1.115 & NA \\
\hline 28 & DNA damage response & Q96QV6 & Histone $\mathrm{H} 2 \mathrm{~A}$ type 1-A & $\mathrm{HIST} 1 \mathrm{H} 2 \mathrm{AA}$ & 205 & 1 & 40.5 & 1.006 & NA \\
\hline 29 & Cell proliferation & Q06830 & Peroxiredoxin-1 & PRDX1 & 114 & 3 & 31.2 & 1.098 & 0.987 \\
\hline 30 & Cell proliferation & P22392 & Nucleoside diphosphate kinase B & NME2 & 142 & 5 & 47.4 & 0.924 & NA \\
\hline 31 & Cell cycle & P85299 & Proline-rich protein 5 & SMR3A & 39 & 1 & 1.8 & 1.048 & NA \\
\hline 32 & $\begin{array}{l}\text { G2/M transition of } \\
\text { mitotic cell cycle }\end{array}$ & P07437 & Tubulin beta chain & TUBB & 660 & 5 & 31.8 & 0.927 & 0.508 \\
\hline 33 & Apoptotic process & P02545 & Prelamin-A/C & LMNA & 56 & 2 & 5.9 & 1.585 & 1.457 \\
\hline 34 & Apoptotic process & P23528 & Cofilin-1 & CFL1 & 101 & 1 & 17.5 & 1.503 & 0.735 \\
\hline
\end{tabular}


Table 2 List of iTRAQ-identified proteins regulated by TIIA (Continued)

\begin{tabular}{|c|c|c|c|c|c|c|c|c|c|}
\hline 35 & Apoptotic process & P05783 & Keratin, type I cytoskeletal 18 & KRT18 & 350 & 8 & 36 & 1.327 & 2.884 \\
\hline 36 & Apoptotic process & P04264 & Keratin, type II cytoskeletal 1 & KRT1 & 1877 & 38 & 10.7 & 1.088 & NA \\
\hline 37 & Apoptotic process & O43707 & Alpha-actinin-4 & ACTN4 & 324 & 10 & 14.3 & 1.054 & 1.560 \\
\hline 38 & Apoptotic process & P61978 & $\begin{array}{l}\text { Heterogeneous nuclear } \\
\text { ribonucleoprotein K }\end{array}$ & HNRNPK & 221 & 5 & 16.6 & 0.938 & 0.760 \\
\hline 39 & Apoptotic process & P30101 & Protein disulfide-isomerase A3 & PDIA3 & 40 & 1 & 9.7 & 0.702 & 0.889 \\
\hline 40 & Apoptotic process & P11021 & 78 kDa glucose-regulated protein & HSPA5 & 191 & 3 & 22.3 & 0.633 & 1.859 \\
\hline 41 & Angiogenesis & P19338 & Nucleolin & $\mathrm{NCL}$ & 242 & 6 & 20.4 & 1.242 & 0.504 \\
\hline 42 & Angiogenesis & P07355 & Annexin A2 & ANXA2 & 412 & 14 & 51.9 & 1.217 & 1.692 \\
\hline 43 & Cytoskeleton organization & P15311 & Ezrin & EZR & 129 & 4 & 17.6 & 1.377 & 2.328 \\
\hline 44 & Cytoskeleton organization & P08727 & Keratin, type I cytoskeletal 19 & KRT19 & 404 & 3 & 39.3 & 1.329 & 2.486 \\
\hline 45 & Cytoskeleton organization & P05787 & Keratin, type II cytoskeletal 8 & KRT8 & 813 & 19 & 52 & 1.317 & 2.486 \\
\hline 46 & Cytoskeleton organization & P07737 & Profilin-1 & PFN1 & 281 & 5 & 34.3 & 0.923 & 0.696 \\
\hline 47 & Actin crosslink formation & P21333 & Filamin-A & FLNA & 64 & 1 & 2.2 & 1.055 & 1.644 \\
\hline 48 & $\begin{array}{l}\text { Microtubule cytoskeleton } \\
\text { organization }\end{array}$ & Q9BQE3 & Tubulin alpha-1C chain & TUBA1C & 1208 & 23 & 45.7 & 0.869 & 0.717 \\
\hline 49 & DNA repair & P06748 & Nucleophosmin & NPM1 & 145 & 3 & 21.1 & 0.973 & 0.785 \\
\hline 50 & DNA ligation & P12956 & $\begin{array}{l}\text { X-ray repair cross- } \\
\text { complementing protein } 6\end{array}$ & XRCC6 & 76 & 2 & 4.4 & 0.841 & 0.746 \\
\hline 51 & DNA repair & Q13263 & $\begin{array}{l}\text { Transcription intermediary } \\
\text { factor 1-beta }\end{array}$ & TRIM28 & 68 & 2 & 4.8 & 1.021 & 0.841 \\
\hline 52 & DNA replication & P55209 & $\begin{array}{l}\text { Nucleosome assembly } \\
\text { protein } 1 \text {-like } 1\end{array}$ & NAP1L1 & 61 & 1 & 7.4 & 0.913 & 0.895 \\
\hline 53 & DNA replication & Q01105 & Protein SET & SET & 77 & 1 & 3.4 & 0.826 & 0.613 \\
\hline 54 & Nucleosome assembly & P04908 & Histone $\mathrm{H} 2 \mathrm{~A}$ type $1-\mathrm{C}$ & HIST1H2AB & 175 & 2 & 37.7 & 1.166 & NA \\
\hline 55 & Nucleosome assembly & Q99879 & Histone $\mathrm{H} 2 \mathrm{~B}$ type $1-\mathrm{M}$ & HIST1H2BM & 355 & 9 & 55.6 & 1.073 & NA \\
\hline 56 & Nucleosome assembly & Q16695 & Histone H3.1 t & HIST3H3 & 95 & 5 & 35.3 & 0.991 & NA \\
\hline 57 & Nucleosome assembly & P62805 & Histone H4 & HIST2H4A & 406 & 14 & 51.5 & 0.991 & NA \\
\hline 58 & Translational elongation & P46783 & $40 \mathrm{~S}$ ribosomal protein $\mathrm{S} 10$ & RPS10 & 82 & 2 & 5.5 & 1.862 & 1.066 \\
\hline 59 & Translational elongation & P46777 & $60 S$ ribosomal protein $L 5$ & RPL5 & 36 & 1 & 4.7 & 1.389 & 1.106 \\
\hline 60 & Translational elongation & P08865 & 40 S ribosomal protein SA & RPSA & 61 & 1 & 14.6 & 1.243 & 1.296 \\
\hline 61 & Translational elongation & P62277 & $40 S$ ribosomal protein $\$ 13$ & RPS13 & 95 & 2 & 23.2 & 1.014 & 1.479 \\
\hline 62 & Translational elongation & P61313 & 605 ribosomal protein L15 & RPL15 & 53 & 1 & 5.9 & 0.983 & 1.129 \\
\hline 63 & Translational elongation & P32969 & 605 ribosomal protein $L 9$ & RPL9 & 78 & 1 & 18.8 & 0.838 & 1.508 \\
\hline 64 & Translational elongation & P23396 & $40 S$ ribosomal protein $\mathrm{S3}$ & RPS3 & 69 & 3 & 23.9 & 0.845 & 1.240 \\
\hline 65 & Translational elongation & P13639 & Elongation factor 2 & EEF2 & 451 & 7 & 24.1 & 0.796 & 2.148 \\
\hline 66 & Translational elongation & P62249 & $40 S$ ribosomal protein S16 & RPS16 & 65 & 1 & 25.3 & 1.042 & 1.397 \\
\hline 67 & Translational elongation & P50914 & 605 ribosomal protein L14 & RPL14 & 80 & 1 & 25.6 & 0.744 & 1.316 \\
\hline 68 & Translational elongation & P39019 & $40 S$ ribosomal protein $\mathrm{S} 19$ & RPS19 & 76 & 2 & 31 & 0.702 & 1.710 \\
\hline 69 & Translational elongation & Q02543 & $60 S$ ribosomal protein L18a & RPL18A & 50 & 1 & 5.1 & 0.709 & 1.369 \\
\hline 70 & Translational elongation & P46778 & 605 ribosomal protein L21 & RPL21 & 58 & 1 & 9.4 & 0.609 & 1.377 \\
\hline 71 & Translational elongation & P18124 & 605 ribosomal protein $L 7$ & RPL7 & 58 & 1 & 11.3 & 0.538 & 1.304 \\
\hline 72 & Translational elongation & P15880 & 40 S ribosomal protein $\mathrm{S} 2$ & RPS2 & 38 & 1 & 11.3 & 0.333 & 1.370 \\
\hline 73 & RNA metabolic process & P55010 & $\begin{array}{l}\text { Eukaryotic translation initiation } \\
\text { factor } 5\end{array}$ & EIF5 & 51 & 1 & 3.5 & 2.675 & 1.248 \\
\hline 74 & RNA metabolic process & P07910 & $\begin{array}{l}\text { Heterogeneous nuclear } \\
\text { ribonucleoproteins C1/C2 }\end{array}$ & HNRNPC & 158 & 2 & 20.3 & 0.917 & 0.682 \\
\hline
\end{tabular}


Table 2 List of iTRAQ-identified proteins regulated by TIIA (Continued)

\begin{tabular}{|c|c|c|c|c|c|c|c|c|c|}
\hline 75 & RNA metabolic process & 014979 & $\begin{array}{l}\text { Heterogeneous nuclear } \\
\text { ribonucleoprotein D-like }\end{array}$ & HNRNPDL & 63 & 2 & 6.4 & 0.810 & NA \\
\hline 76 & RNA metabolic process & Q32P51 & $\begin{array}{l}\text { Heterogeneous nuclear } \\
\text { ribonucleoprotein A1-like } 2\end{array}$ & HNRNPA1L2 & 250 & 7 & 29.4 & 0.764 & 1.117 \\
\hline 77 & RNA metabolic process & P60842 & Eukaryotic initiation factor $4 \mathrm{~A}-\mathrm{I}$ & EIF4A1 & 115 & 2 & 16.3 & 0.725 & 0.595 \\
\hline 78 & RNA metabolic process & P52597 & $\begin{array}{l}\text { Heterogeneous nuclear } \\
\text { ribonucleoprotein F }\end{array}$ & HNRNPF & 116 & 2 & 9.6 & 0.647 & 0.699 \\
\hline 79 & Epidermis development & P02533 & Keratin, type I cytoskeletal 14 & KRT14 & 266 & 1 & 21.4 & 2.455 & 0.667 \\
\hline 80 & Epidermis development & P35527 & Keratin, type I cytoskeletal 9 & KRT9 & 506 & 16 & 26.6 & 1.072 & NA \\
\hline 81 & Ectoderm development & P04259 & Keratin, type II cytoskeletal 6B & KRT6B & 432 & 1 & 23 & 1.225 & 22.537 \\
\hline 82 & $\begin{array}{l}\text { Sulfur amino acid } \\
\text { metabolic process }\end{array}$ & P23526 & Adenosylhomocysteinase & $\mathrm{AHCY}$ & 43 & 1 & 9.7 & 1.798 & 0.967 \\
\hline 83 & $\begin{array}{l}\text { Epithelial to mesenchymal } \\
\text { transition }\end{array}$ & Q99729 & $\begin{array}{l}\text { Heterogeneous nuclear } \\
\text { ribonucleoprotein } A / B\end{array}$ & HNRNPAB & 62 & 1 & 2.4 & 1.640 & 0.543 \\
\hline 84 & $\begin{array}{l}\text { Energy reserve metabolic } \\
\text { process }\end{array}$ & P05141 & ADP/ATP translocase 2 & SLC25A5 & 58 & 1 & 5.7 & 1.412 & 1.234 \\
\hline 85 & Embryo development & P60174 & Triosephosphate isomerase & TPI1 & 63 & 1 & 4.5 & 1.362 & 0.636 \\
\hline 86 & $\mathrm{NADH}$ metabolic process & P40926 & $\begin{array}{l}\text { Malate dehydrogenase, } \\
\text { mitochondrial }\end{array}$ & $\mathrm{MDH} 2$ & 46 & 1 & 3.3 & 1.262 & 1.022 \\
\hline 87 & GTP catabolic process & P68371 & Tubulin beta- $4 \mathrm{~B}$ chain & TUBB4B & 490 & 2 & 31 & 1.216 & 0.572 \\
\hline 88 & $\begin{array}{l}\text { Cellular membrane } \\
\text { organization }\end{array}$ & P63104 & 14-3-3 protein zeta/delta & YWHAZ & 224 & 2 & 34.3 & 1.208 & 1.016 \\
\hline 89 & Muscle contraction & P07951 & Tropomyosin beta chain & TPM2 & 44 & 1 & 16.2 & 1.418 & 0.744 \\
\hline 90 & $\begin{array}{l}\text { Activation of MAPKK } \\
\text { activity }\end{array}$ & P31946 & 14-3-3 protein beta/alpha & YWHAB & 188 & 2 & 24.8 & 1.201 & 0.616 \\
\hline 91 & $\begin{array}{l}\text { Protein export from } \\
\text { nucleus }\end{array}$ & P63241 & $\begin{array}{l}\text { Eukaryotic translation initiation } \\
\text { factor } 5 \mathrm{~A}-1\end{array}$ & EIF5AL1 & 54 & 1 & 7.8 & 1.105 & 0.772 \\
\hline 92 & Keratinization & P35908 & $\begin{array}{l}\text { Keratin, type II cytoskeletal } 2 \\
\text { epidermal }\end{array}$ & KRT2 & 1260 & 21 & 38.2 & 0.974 & NA \\
\hline 93 & $\begin{array}{l}\text { Cellular response to } \\
\text { calcium ion }\end{array}$ & P13645 & Keratin, type I cytoskeletal 10 & KRT10 & 1903 & 29 & 45 & 0.963 & 1.831 \\
\hline 94 & Response to hypoxia & P14618 & Pyruvate kinase PKM & PKM & 352 & 10 & 26.9 & 0.918 & 0.811 \\
\hline 95 & RNA transport & P22626 & $\begin{array}{l}\text { Heterogeneous nuclear } \\
\text { ribonucleoproteins A2/B1 }\end{array}$ & HNRNPA2B1 & 199 & 4 & 18.7 & 0.881 & 0.281 \\
\hline 96 & $\begin{array}{l}\text { Histone mRNA metabolic } \\
\text { process }\end{array}$ & P62318 & $\begin{array}{l}\text { Small nuclear ribonucleoprotein } \\
\text { Sm D3 }\end{array}$ & SNRPD3 & 45 & 1 & 11.1 & 0.931 & 0.479 \\
\hline 97 & $\begin{array}{l}\text { Positive regulation of } \\
\text { protein phosphorylation }\end{array}$ & P63244 & $\begin{array}{l}\text { Guanine nucleotide-binding } \\
\text { protein subunit beta-2-like } 1\end{array}$ & GNB2L1 & 68 & 1 & 7.9 & 0.860 & 1.189 \\
\hline 98 & GTP catabolic process & P68104 & Elongation factor 1-alpha 1 & EEF1A1 & 543 & 18 & 34 & 0.859 & 1.596 \\
\hline 99 & Response to virus & P26641 & Elongation factor 1-gamma & EEF1G & 195 & 4 & 9.6 & 0.763 & 1.257 \\
\hline 100 & Cilium assembly & Q15051 & $\begin{array}{l}\text { IQ calmodulin-binding } \\
\text { motif-containing protein } 1\end{array}$ & IQCB1 & 41 & 1 & 2 & 0.759 & 1.429 \\
\hline 101 & Cell redox homeostasis & P07237 & Protein disulfide-isomerase & $\mathrm{P} 4 \mathrm{HB}$ & 86 & 3 & 7.5 & 0.710 & 1.076 \\
\hline 102 & RNA binding & Q92804 & $\begin{array}{l}\text { TATA-binding protein-associated } \\
\text { factor } 2 \mathrm{~N}\end{array}$ & TAF15 & 56 & 1 & 2.9 & 0.614 & 0.372 \\
\hline
\end{tabular}

levels in AGS cells compared with the control sample (Figure 4D).

TIIA arrests the cell cycle at the $G_{2} / M$ phase transition The ability to monitor response to regulation of the cell cycle is an enriched function from our transcriptomics data (Figure 2A and Table 1). We treated AGS cells with different concentrations of TIIA and measured DNA distributions by using flow cytometry to detect the cell cycle distribution of a population of cancer cells. The percentage of AGS cells in the $G_{2} / M$ phase increased up to $13.68 \%$ above control levels after $5.3 \mu \mathrm{M}$ TIIA treatment, 

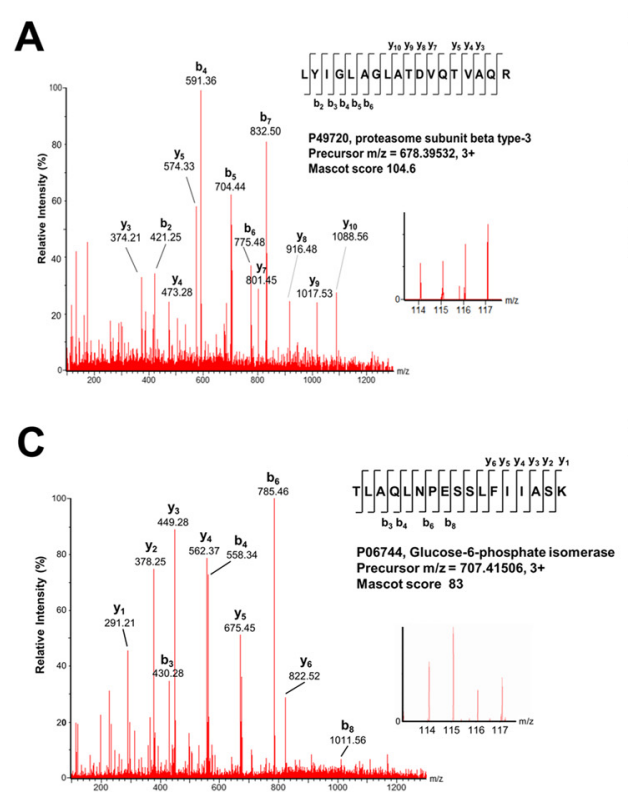

Figure 3 MS/MS spectra of peptide and protein levels for PSMB3, RS2 and G6PI. MS/MS spectra of peptides from PSMB3 (A), RS2 (B) and G6PI (C) are reported along with iTRAQ ion reporter quantification. Ion, $\mathrm{m} / \mathrm{z} 114$ and 115 represent peptides collected from control samples. Ion, m/z 116 and 117 represent peptides collected from TIIA-treated samples. (D) Protein expression levels of PSMB3, RS2 and G6PI were examined using western blotting analysis, with $\beta$-actin as an internal control. All experiments were repeated three times with independent samples.

showing that TIIA induces cell cycle arrest of AGS at $\mathrm{G}_{2} / \mathrm{M}$ in a dosage-dependent manner (Figure $5 \mathrm{~A}$ ).

As indicated in Table 1, CDK1, cyclin B1 and Cdc25C are associated with the cell cycle at the $G_{2} / M$ phase, and were identified in our transcriptomics data. CDK1 activation can regulate the progression of the cell cycle from the $G_{2}$ to the $M$ phase, which is dependent on coordination with cyclin B $[24,25]$. The activation of the CDK1/ cyclin-B complex is maintained through phosphorylation of Thr161 and dephosphorylation of Thr14 and Tyr15 in CDK1. Dephosphorylation of Thr14 and Tyr15 in CDK1 is catalyzed by phosphatase $\mathrm{Cdc} 25 \mathrm{C}$, which is considered a rate-limiting step for the $G_{2}$ to $M$ phase transition $[24,25]$. Previous reports suggest monitoring the alteration of CDK1, cyclin B1, Cdc25C, and phospho-CDK1 (CDK1-Thr161) protein expressions is a useful way to validate the occurrence of cell cycle arrest at the $G_{2} / M$ transition [26]. For these reasons, to confirm whether TIIA induces cell cycle arrest at $G_{2} / M$ in gastric cancer cells, we treated AGS cells with TIIA at a concentration of $5.3 \mu \mathrm{M}\left(\mathrm{IC}_{50}\right)$, and then measured protein expression levels using western blotting analysis. Levels of phosphoCDK1 (CDK1-Thr161), cyclin B1, and Cdc25C were all reduced in cells treated with TIIA (Figure 5B). Our results indicate that TIIA treatment induced characteristic cell cycle arrest at $\mathrm{G}_{2} / \mathrm{M}$ in AGS cells by altering cyclin B1 and Cdc25C expression as well as the phosphorylation of CDK1.

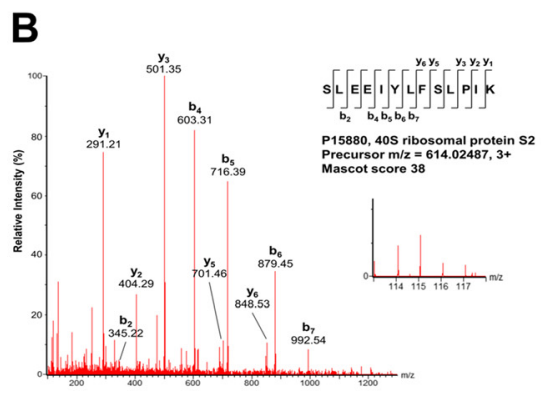

D
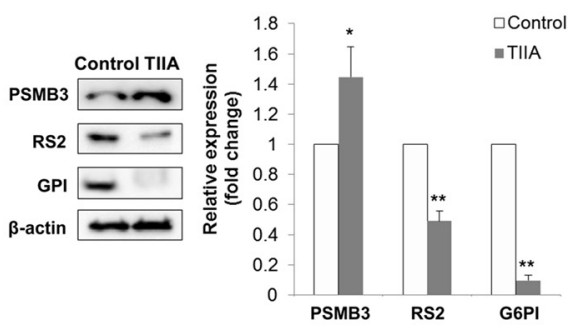

TIIA treatment causes apoptosis and reorganization of actin filaments and microtubules

Our cell cycle analysis also indicated that levels of cells in the sub- $G_{1}$ phase were increased $5.5 \%$ above control levels under $5 \mu \mathrm{M}$ TIIA treatment conditions (Figure $5 \mathrm{~A}$ ). A significant increase of cells in the sub-G1 phase is widely accepted as a sign of apoptosis induction [27]. As our transcriptomics and proteomics data (Figure 2A and Table 1) show, apoptosis-related genes could be induced by TIIA. We treated AGS cells at different concentrations of TIIA and detected the proportions of cells undergoing apoptosis or necrosis using flow cytometry. Our results show that the proportion of cells undergoing apoptosis (including early- and late-phase apoptosis) significantly increased by $15.3 \%$ above control levels under $5.3 \mu \mathrm{M}$ TIIA treatment conditions, showing that TIIA induced apoptosis of AGS cells in a dosage-dependent manner (Figure 6A).

It is widely understood that reorganization of the cytoskeleton, including actin filaments and microtubules, plays a crucial role in apoptosis [28,29]. Links between this process and TIIA treatment can be seen in our transcriptomics and proteomics data (Figure 2A and Table 1). To detect whether the cytoskeletons of AGS cells undergo reorganization after TIIA exposure, we treated AGS cells with TIIA at different concentrations, then examined the consequent distribution of actin filaments and microtubules using immunofluorescence staining. Many cells were 

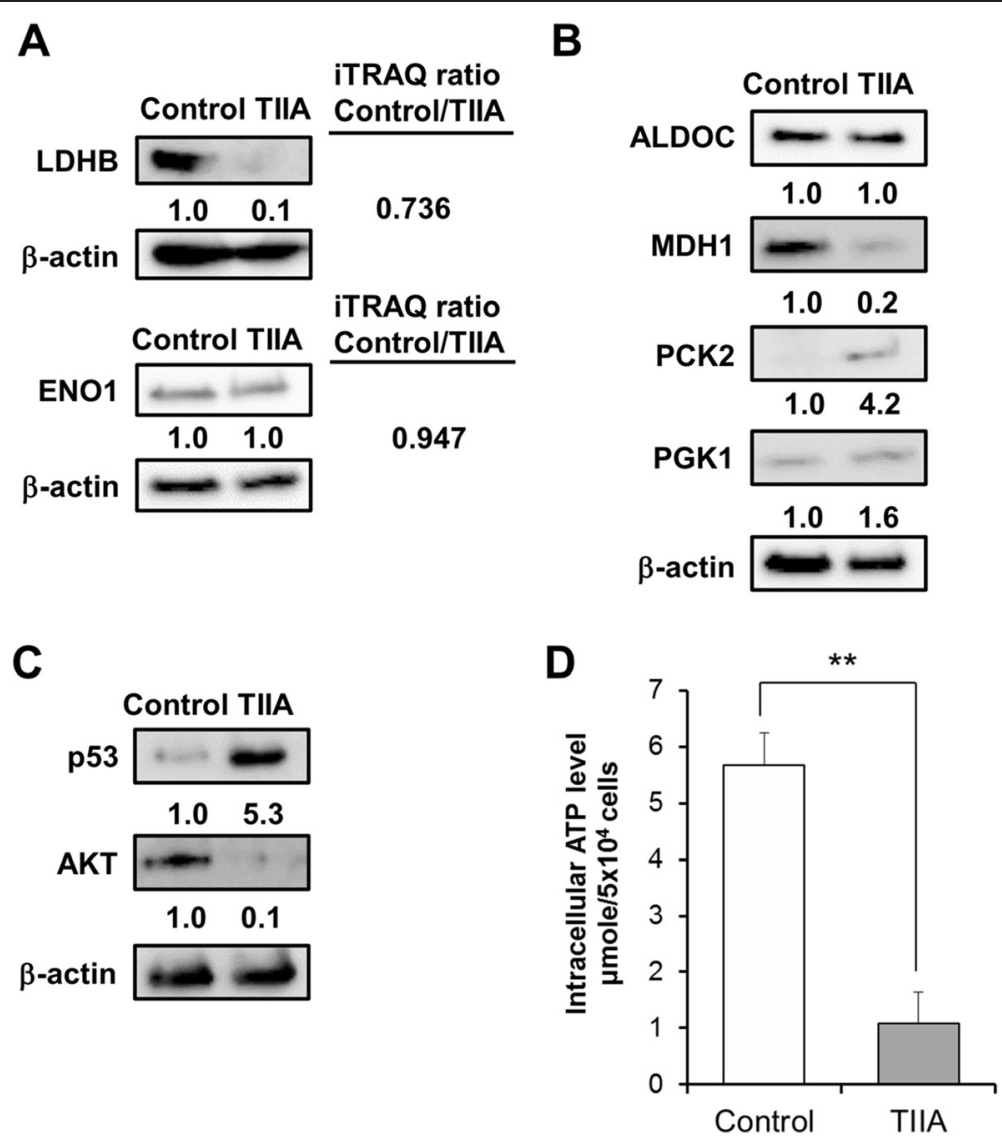

Figure 4 Treatment with TIIA changes the expression of glucose metabolism-related proteins in AGS cells. (A) The expression of iTRAQ-identified proteins, LDHB and ENO1 was estimated using western blotting. (B) The expression of ALDOC, MDH1, PCK2 and PGK1 in AGS cells treated with TIIA was estimated using western blotting. The levels of (C) tumor suppressor gene, p53, and the oncogene AKT, and (D) intracellular ATP, were examined in AGS cells treated with TIIA. $\beta$-actin was used as an internal control.

seen to manifest shrinking morphology after TIIA treatment (Figure 6B). Actin filaments under TIIA treatment became more condensed, especially at the cell periphery, and underwent crumbling. On the other hand, microtubules aggregated to become thick bundles, and were distributed along nuclear fragmentation sites with condensed chromatin (Figure 6B). These kinds of cytoskeletal reorganizations, combined with nuclear fragmentation, are all characteristic of apoptosis [2,28-30], showing that TIIA induced cytoskeleton reorganization arising from apoptosis in AGS cells.

\section{TIIA triggers $\gamma-\mathrm{H} 2 \mathrm{AX}$ nuclear foci in response to DNA double strand breaks}

Based on our previous results, TIIA could induce DNA damage in gastric cancer cells (Figure 2A and Table 1). DNA damage, including double strand breaks (DSB), often leads to genetic instability; proper cellular responses to DNA damage are crucial for cell function and survival [31,32]. Previous studies have shown that phosphorylation of the histone variant $\mathrm{H} 2 \mathrm{AX}$, producing $\gamma-\mathrm{H} 2 \mathrm{AX}$ at nuclear foci, plays an important role in the DNA damage response triggered by DSB [33,34]. The change in H2AX levels was also apparent in our data (Table 1). To examine whether TIIA triggers DNA damage in gastric cancer cells, we treated AGS cells with different levels of TIIA to examine the subsequent localization of $\gamma-\mathrm{H} 2 \mathrm{AX}$ using immunofluorescence staining. Numerous $\gamma$-H2AX foci were localized in the nuclei of TIIA treated cells, while $\gamma$-H2AX was only represented in a few foci in control cells (Figure 7A). Increased protein expression of $\gamma$-H2AX was also detected in TIIA-treated cells (Figure 7B). These results suggest that TIIA triggers DSB, triggering a DNA damage response in AGS cells.

\section{Discussion}

Botanical herbs have been used for disease treatment and prevention, and as alternative and complementary therapies [35]. For instance, paclitaxel isolated from one kind of botanical herb, Taxus brevifolia, has been used as second-line chemotherapy for advanced or recurrent gastric cancer [36]. In this study, we treated gastric 


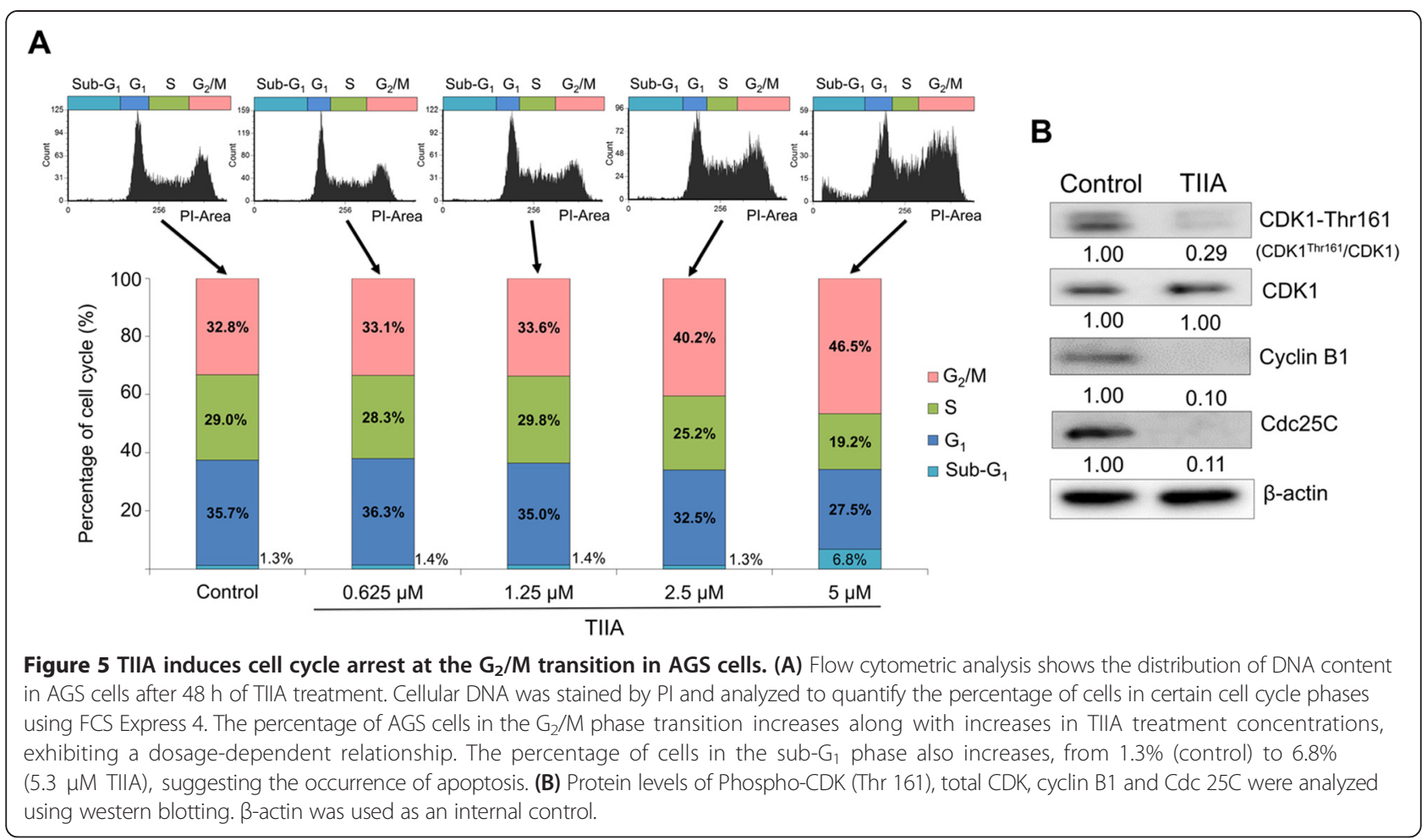

A

TIIA

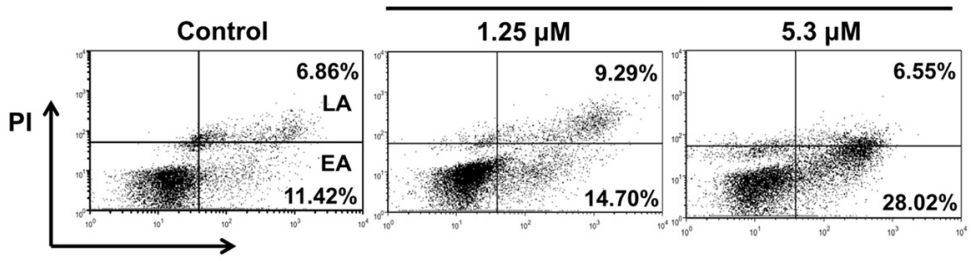

Annexin V-FITC

B

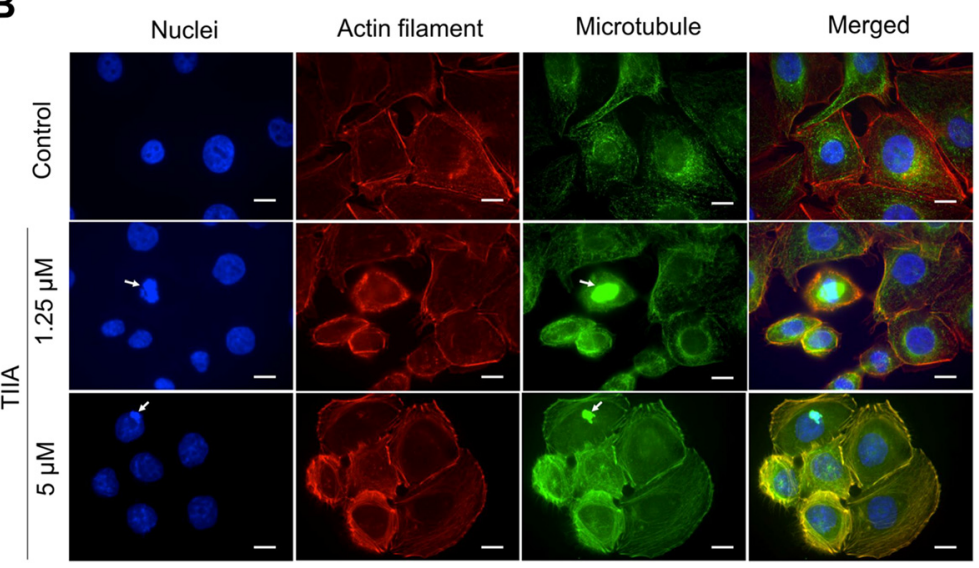

Figure 6 TIIA induces apoptosis and reorganization of cytoskeleton in AGS cells. (A) AGS cells were treated with different levels of TIIA (1.25 $\mu M$ and $5.3 \mu \mathrm{M}$ ). Treated cells were stained with annexin A5 and PI and their apoptotic condition was analyzed by flow cytometry. EA denotes early apoptosis; LA denotes late apoptosis. (B) Images of AGS cells were obtained by fluorescence microscopy after TIIA treatment for 48 hr. Nuclei were stained with DAPI (blue), actin filaments were stained with rhodamine-labeled phalloidin (red), and microtubules were stained with mouse anti-a-tubulin antibody and the corresponding FITC-conjugated secondary anti-mouse lgG antibody (green). Arrows indicate nuclear fragmentation sites with condensed chromatin. Microtubules are densely packed at these sites; this condensation is an important step during the apoptotic process [30]. Scale bars represent $10 \mu \mathrm{m}$. 
A

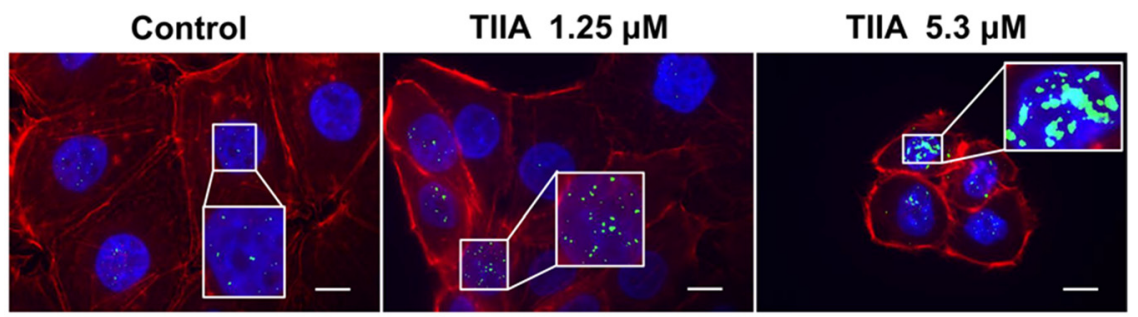

B
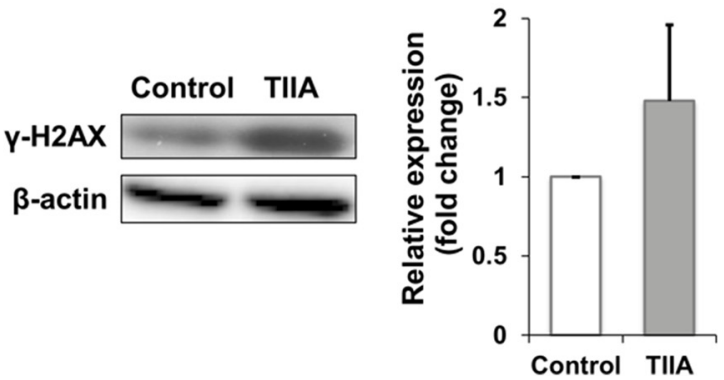

Figure 7 TIIA triggers DNA double-strand breaks in AGS cells. (A) Images of AGS cells were obtained by fluorescence microscopy after 48 hr of TIIA treatment. Nuclei were stained with DAPI (blue), actin filaments were stained with rhodamine-labeled phalloidin (red), and $\gamma$-H2AX were stained with mouse anti- $-\mathrm{H} 2 \mathrm{AX}$ antibody and the corresponding FITC-conjugated secondary anti-mouse IgG antibody (green). Each zoomed panel shows representative $\gamma-\mathrm{H} 2 \mathrm{AX}$ distributions in detail. Scale bars represent $10 \mu \mathrm{m}$. (B) Protein expression of $y-\mathrm{H}_{2} \mathrm{AX}$ increases under an $\mathrm{C}_{50}$ dose of TIIA; samples were analyzed by Western blotting with $\beta$-actin as internal control. Histogram values for fold change are expressed as mean \pm SD from three independent experiments.

cancer with TIIA, which can be used to improve heart function by limiting apoptosis or oxidative damage [37]. Recently, many studies have shown that TIIA exhibits anti-tumor potential [10-16], and that on cancers such as breast cancer, prostate cancer, and leukemia, it can induce the mitochondria-dependent apoptosis pathway [38-40]. In MKN45 gastric cancer cells, TIIA was reported to inhibit cell growth, induce $\mathrm{G}_{2} / \mathrm{M}$ cell cycle arrest and apoptosis $[16,41]$. However, few of them actually constructed possible pathways or mechanisms in gastric cancer.

Genes for glycolysis are overexpressed in 70\% of all human cancers worldwide, including gastric cancer [42]. By comparing our transcriptomics and proteomics data, we are the first to propose that the transformation of glucose metabolism, glycolysis and gluconeogenesis in gastric cancer cells is a major biological process that is regulated by TIIA treatment. An enzyme involved in glycolysis, G6PI, catalyzes the reversible isomerization of glucose-6phosphate to fructose-6-phosphate, and is downregulated by TIIA [43]. Increased synthesis of G6PI, known as autocrine motility factor (AMF), is considered to be a unique feature of cancer cells, which stimulates cell growth and contributes to cancer metastasis and malignancy [44-47]. AMF can also down-regulate caspase-9 and Apaf-1, making cancer cells more resistant to mitochondriadependent apoptosis [48]. Previous studies have reported that TIIA can induce mitochondria-dependent apoptosis by regulating caspase- 9 and Apaf- 1 in several types of cancer [38-40]. In gastric cancer, we also found that TIIA may induce apoptosis (Figure 6A). Based on our results, we suggest that TIIA might induce the occurrence of apoptosis by suppressing G6PI expression, which decreases glucose consumption and inhibits glycolysis in cancer cells.

In gluconeogenesis, expression of LDHB, one of the subunits of lactate dehydrogenase (LDH), which converts lactate to pyruvate, was shown to decrease in AGS cells after TIIA treatment. Pyruvate is the end product of glycolysis and contributes to gluconeogenesis, acetyl-CoA which enters the Krebs (TCA) cycle, lipid synthesis and nonessential amino acid synthesis for proliferative responses in tumor cells [17]. Decreased LDHB expression might enhance negative regulation of the Warburg effect, which mediates pyruvate into lactate and back in tumor cells [49]. In mouse immortalized cell lines, LDHB is critical in the mechanistic target of rapamycin (mTOR) pathway to induce tumor formation [50]. LDHB is also considered as a tumor marker that increases in many cancers because it facilitates tumor growth and cell proliferation [51-53]. Serum $\mathrm{LDH}$ is also considered to be predictors for overall survival of advanced nasopharyngeal carcinoma patients [54]. In gastric cancer cells, we suggest that TIIA treatment might block nutrient supply, which reduces cell survival and proliferation by causing lactate dehydrogenase deficiency. 
MDH1 and PCK2 in mitochondria are used to convert pyruvate to phosphoenolpyruvate. In colon cancer, increased $\mathrm{MDH}$ levels could enhance glycolysis and lead to cell proliferation and tumorigenesis [55]. Silencing PCK2 in colon cancer cells could reduce susceptibility to preoperative 5-fluorouracil-based radiation therapy [56] and responses to high glucose levels [57]. In this study, we found that TIIA treatment can decrease MDH1 expression and increase PCK2 expression (Figure 4B). Increased PGK1 in gastric cancer is considered as a biomarker of advanced gastric cancer and is followed by increasing intracellular ATP levels [58]. However, TIIA reduced intracellular ATP levels and slightly up-regulated PGK1, which indicates that some functions of TIIA are still unclear. Moreover, the oncogene AKT was down-regulated by TIIA, which can stimulate aerobic glycolysis in cancer cells [59], suggesting that TIIA has the potential to be used as chemotherapy for gastric cancer because of its effectiveness in transforming glucose metabolism (Figure 8).

The glucose metabolic switch is associated with the cell cycle, apoptosis and DNA repair in tumor cells [17]. Our transcriptomics analyses and proteomics data also showed that TIIA can regulate these functions and their related proteins, such as PSMB3 and RS2. Previous studies have shown that the expression of PSMB3 and RS2 is involved the development of cancer [60,61]. PSMB3, which belongs to the proteasome B-type family, was upregulated by TIIA. Proteasomes are necessary for the DNA damage response, and accumulate at double strand break sites to recruit other repair proteins [62]. TIIA treatment increased the likelihood of the occurrence of DNA damage in gastric cancer cells (Figure 7), which might stimulate cancer cells to increase PSMB3 expression.

Moreover, RS2, as a cancer-related ribosomal protein, was down-regulated by TIIA. Increased RS2 is present when p53 mutates, which occurs in cell cycle progression or apoptosis in response to DNA damage [60]. Elevated expression of $p 53$, cell cycle arrest in the $G_{2} / M$ phase, apoptosis and cytoskeleton reorganization were observed in AGS cells following TIIA treatment. DNA damage is one of the major causes of cell cycle arrest in the $G_{2} / M$ phase [63]. Cytoskeleton reorganization, including the redistribution of actin and microtubules, is a characteristic of chromatin remodeling during apoptosis [64]. This has also been observed in cancer cells treated with clinical anti-cancer drugs, such as etoposide, doxorubicin and taxol [65].

\section{Conclusions}

We integrate transcriptomics and proteomics data to uncover TIIA-regulated mechanisms in gastric cancer. In glycolysis and gluconeogenesis, TIIA reduces glucose consumption and the production of pyruvate by regulating
G6PI, LDHB, MDH1, PCK2 and PGK1 expression. AKT decreases and p53 increases in response to apoptosis and DNA damage in gastric cancer cells following TIIA treatment, while the glucose metabolism switch induced by the transformation of oncogenes is destroyed (Figure 8). We suggest that TIIA treatment could cause cell stress, nutrient deficiency and DNA damage, to induce cycle arrest at the $G_{2} / M$ transition, apoptosis and cytoskeleton reorganization, all of which would inhibit cell proliferation. In this study, we provide new insight into the TIIA regulatory mechanism in gastric cancer cells, so that future cancer research can improve therapeutic strategies.

\section{Methods}

\section{Cell culture}

Human stomach adenocarcinoma AGS (CRL-1739; ATCC) cells were grown in 90\% RPMI 1640 medium (Biological Industries, Beit Haemek, Israel) supplemented with 10\% fetal bovine serum (Biological Industries). Cells were cultured at $37^{\circ} \mathrm{C}$ in an incubator with controlled humidified atmosphere containing $5 \% \mathrm{CO}_{2}$. Cells were disaggregated for subculturing with trypsin plus ethylenediaminetetraacetic acid (EDTA), then spun down by centrifugation at $1200 \mathrm{rpm}$ for $5 \mathrm{~min}$, after which the pellet was resuspended in culture medium.

\section{TIIA preparation}

Tanshinone IIA powder (T4952; Sigma-Aldrich) was dissolved in dimethyl sulfoxide (DMSO) (BioShop), which was diluted to applicable concentrations for treatment.

\section{Growth curves and IC $\mathrm{C}_{50}$ measurement}

Growth curves of AGS cells were recorded by an RTCA $\mathrm{DP}^{\oplus}$ system (xCELLigence ${ }^{\mathrm{Tm}}$; Roche Applied Science \& ACEA Biosciences). Cells were treated with TIIA or $0.1 \%$ DMSO as control for $72 \mathrm{hr}$ after $24 \mathrm{hr}$ of seeding $(5,000$ cells/well in 96-well E-plates). TIIA treatment concentrations were $0.1 \mu \mathrm{M}, 1 \mu \mathrm{M}, 5.3 \mu \mathrm{M}$, and $10 \mu \mathrm{M} ; 0.1 \%$ DMSO dissolved in culture medium was used as control. Each condition was performed in triplicate. The $\mathrm{IC}_{50}$ of TIIA at $48 \mathrm{hr}$ was calculated with RTCA software 1.2 (xCELLigence $^{\mathrm{rm}}$ ) by using AGS cell growth curves under TIIA treatments of $0.1 \mu \mathrm{M}, 1 \mu \mathrm{M}, 5.3 \mu \mathrm{M}$, and $10 \mu \mathrm{M}$.

\section{Colony formation assay}

AGS cells were treated with TIIA or $0.1 \%$ DMSO control medium for 5 days after $24 \mathrm{hr}$ of seeding (2,500 cells/well in 6-well plates). TIIA treatment concentrations were $0.53 \mu \mathrm{M}, 1.06 \mu \mathrm{M}$, and $5.3 \mu \mathrm{M}$; 0.1\% DMSO dissolved in culture medium was used as control. After treatment, cells were fixed with methanol for $10 \mathrm{~min}$, stained with $200 \mu \mathrm{g} / \mathrm{mL}$ crystal violet (Sigma-Aldrich) for $10 \mathrm{~min}$, and then colonies were counted using AlphaView SA 3.4.0 (ProteinSimple). Each condition was performed in triplicate. 


\section{Tanshinone IIA}

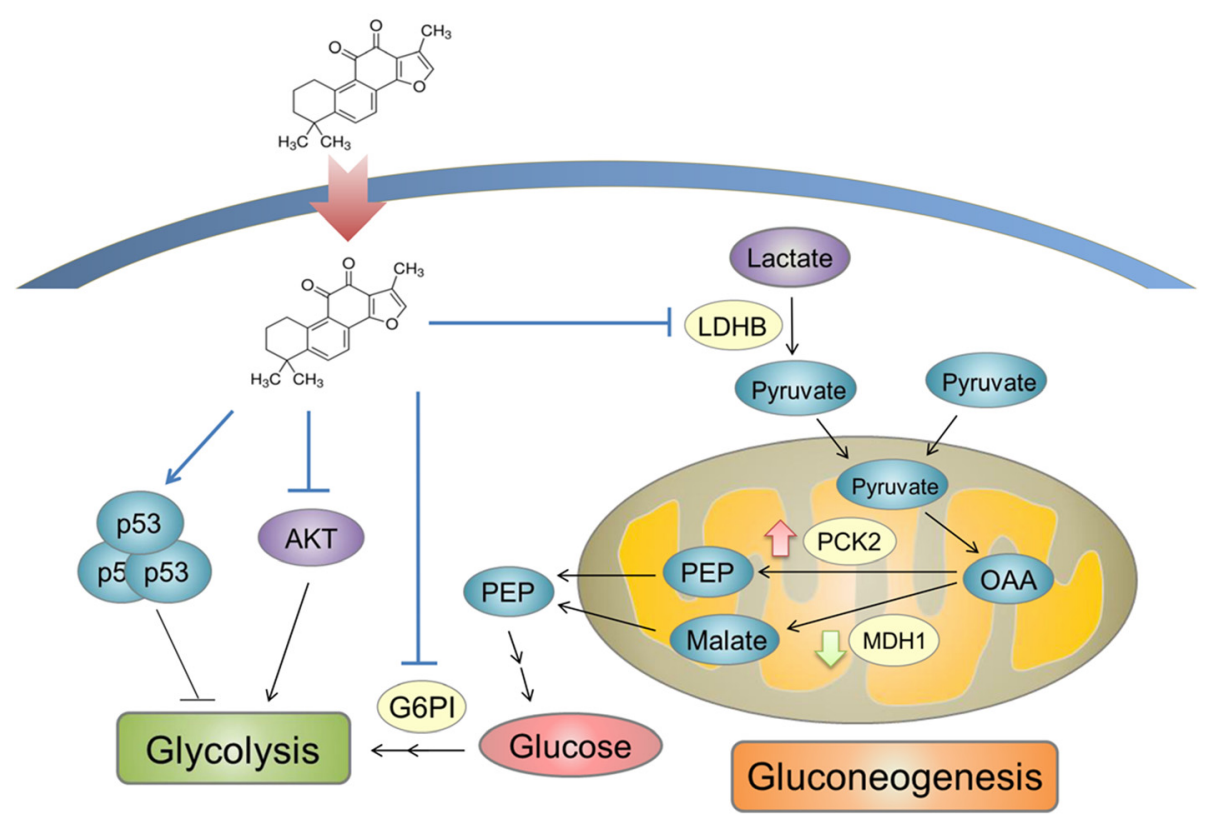

Figure 8 Schematic representation of TIIA blocking glucose metabolism in gastric cancer cells. In tumor cells, glucose is consumed to produce ATP, and the glycolytic intermediates are used for biosynthetic pathways. Proto-oncogene, AKT, stimulates glycolysis and the tumor suppression gene, p53, suppresses glucose metabolism via several pathways. After TIIA treatment, intracellular ATP levels and AKT expression decreases, and p53 expression increases. In the second step of glycolysis, glucose-6-phosphate isomerase, acting as an enzyme, was down-regulated by TIIA treatment. We also found that TIIA dysregulates gluconeogenesis by suppressing LDHB and MDH1 expression, and enhancing PCK2 expression. TIIA promotes the activity of these pathways to suppress cancer cell growth.

\section{RNA sequencing and data analysis}

Total RNA was extracted from AGS cells treated with DMSO (control) or TIIA, using TRIzol reagent (Invitrogen, USA) according to the manufacturer's instructions. The quantity and quality of RNA were checked using an Agilent 2100 Bioanalyzer (Agilent Technologies, Santa Clara, CA), and were found to have an RNA Integrity Number (RIN) value of more than 9. Poly(A) mRNA was isolated with oligo(dT)-bound magnetic beads and incubated with fragmentation buffer to form short RNA fragments. Reverse transcriptase and random hexamer primers were used to synthesize the first-strand cDNA, and DNA polymerase I and $\mathrm{RNaseH}$ were used to synthesize the second-strand cDNA. Double stranded cDNA was end-repaired with T4 DNA polymerase, Klenow fragments, and T4 Polynucleotide Kinase, after which a single "A" base was added, and the entire sequence was ligated to Illumina sequencing adapters (Illumina, San Diego, CA). PCR was performed to amplify the fragments. Using Illumina HiSeqTM 2000 (Illumina), the cDNA library was sequenced on a flow cell after validation on an Agilent 2100 Bioanalyzer and ABI StepOnePlus Real-Time PCR System.

After the base calling, the reads with adaptor sequences and low quality scores were removed. The reads with low quality scores are defined as the reads with greater than $10 \%$ of unknown bases $(\mathrm{N})$ or greater than $50 \%$ of low quality bases which quality values are less than 5 . The reads with high quality scores were mapped to the human reference genome hg19 assembly using SOAPaligner in SOAP2 with 2 mismatch allowance [66] and annotated based on the GENCODE [67]. Read counts for individual GENCODE genes were subsequently determined using HTSeq-count (http://www-huber.embl.de/users/ anders/HTSeq), by considering only uniquely mapped reads. Expression of each individual gene was quantified by using the Reads Per Kilobase per Million mapped reads (RPKM) method. The differentially expressed genes were identified by Poisson distribution model [68]. The sequences reported in this study have been deposited in the Sequence Read Archive database with accession number SRP049450.

\section{Functional enrichment analysis}

We used MetaCore version 6.18 (GeneGo, St. Joseph, MI, USA) to perform a gene function analysis and to enrich the functional networks of identified genes collected from RNA-seq. There were 16,110 of 16,603 identified genes eligible for network enrichment via GO Processes and Metabolic Networks analysis. For analysis of differentially expressed genes ( $\mid \log _{2}$ (fold-change) $\left.\mid>1\right), 2,717$ of 2,761 DEGs were eligible for GO Processes enrichment analysis, and displayed classified genes (Table 1). All enrichment 
analysis was tested using the $p$-value threshold $p<0.0001$ for the data inputs.

\section{iTRAQ labeling and LC-MS/MS analysis}

AGS cells were treated with $5.3 \mu \mathrm{M}\left(\mathrm{IC}_{50}\right)$ TIIA or $0.1 \%$ DMSO control medium for $48 \mathrm{hr}$ after $24 \mathrm{hr}$ of seeding $\left(8 \times 10^{4}\right.$ cells/well in 6-well plates). Cells were harvested with trypsin/EDTA and then total proteins were extracted by using lysis buffer (1\% SDS (Bioman), $50 \mathrm{mM}$ Tris- $\mathrm{HCl}$ (pH 6.8), 10\% glycerol), and $1 \times$ protease inhibitor (Bioman) and sonication. Proteins were processed through reduction, alkylation, and gel-assisted trypsin digestion overnight to yield peptides, which were later extracted from the gels as previous methods [69]. Equal amounts of peptides from control and TIIA-treated samples were labeled by different iTRAQ reagents (AB SCIEX; control samples labeled by 114 or 115; TIIA-treated samples labeled by 116 or 117) and incubated at room temperature for $1 \mathrm{hr}$. Peptides were combined together and dried with a centrifugal evaporator (CVE-2000; EYELA). After iTRAQ-labeling, samples were desalted and analyzed by using a LC-ESI-Q-TOF mass spectrometer (Waters SYNAPT ${ }^{\circ}$ G2 HDMS; Waters Corp.). Samples were injected into a $180 \mathrm{~mm} \times 2 \mathrm{~cm}$ capillary trap column and separated by a $75 \mathrm{~mm} \times 25 \mathrm{~cm}$ nanoACQUITY UPLC ${ }^{\mathrm{tm}} 1.7 \mathrm{~mm}$ Ethylene Bridged Hybrid C18 column using a nanoACQUITY Ultra Performance LC $^{\mathrm{max}}$ System (Waters Corp.). The mass spectrometer (MS) was operated in electrospray ionization sensitivity mode, and calibrated with a synthetic human [Glu1]-Fibrinopeptide B solution (1 pmol/ml; Sigma-Aldrich) delivered through a NanoLockSpray ${ }^{\text {mit }}$ source, which was used for accurate mass measurements. Data was acquired in the data directed analysis (DDA) mode, which included one full MS scan $(\mathrm{m} / \mathrm{z}$ 350-1700, $1 \mathrm{~s})$ and three sequential MS/MS scans $(\mathrm{m} / \mathrm{z} 100-1990.1 .5 \mathrm{~s}$ for each scan) on the three most intense ions present in the full scan mass spectrum.

\section{Protein identification}

The peak list resulting from MS/MS spectra was generated by Mascot Distiller v2.3.2 (Matrix Science, London, United Kingdom). Data files were searched against the sequence database (containing 536,789 sequences entries) of the Swiss-Prot human database, using Mascot search engine v2.3.02 (Matrix Science, London, United Kingdom). Both the precursor peptide and fragment ion tolerances were set to $\pm 0.1 \mathrm{Da}$. The search parameter settings were as follows: allowances for two missed cleavages from trypsin digestion and variable modifications of deamidation (NQ), oxidation $(\mathrm{M})$, iTRAQ ( $\mathrm{N}$ terminal), iTRAQ (K), and methylthio (C). The peptide charge was set to $M_{r}$ the instrument was set to ESI-QUAD-TOF, and the decoy database was searched. Mascot search results were filtered using "Significance threshold" set at $p<0.05$ and "Ions score or expect cut-off" set at 0.05 . To evaluate the false discovery rate (FDR), we compared a decoy database search against a randomized decoy database created by Mascot using identical search parameters and validation criteria. FDR was calculated as $D / R \times 100 \%$, where $D$ and $R$ are the number of matches above identity threshold using the decoy and real databases, respectively. The mass spectrometry proteomics data have been uploaded to the ProteomeXchange Consortium [70] via the PRIDE partner repository with the data set identifier PXD000998 and DOI 10.6019/PXD000998.

For protein quantitation, signature ions $(\mathrm{m} / \mathrm{z}=114,115$, 116 and 117) and peptides were detected and analyzed using Multi-Q software (v1.6.5.4) [71]. Peptides that satisfied the following four criteria were subjected to further analysis. Firstly, the peptide is labeled with iTRAQ tags; secondly, the peptide has an ion score higher than the Mascot identity score $(p<0.05)$; thirdly, the peptide is nondegenerate (unique); fourthly, the ITRAQ signature ion peak intensity (ion count) of the peptide is within the dynamic range (the peak intensity of each iTRAQ signature ion must be $>0$, and the average of the peak intensities of all iTRAQ signature ions must be $\geq 30$ ). Before quantitation of the expression of each protein, the peak intensity of the iTRAQ signature ion was normalized, as "Method 1" of our previous study [72]. To determine the expression ratio of identified proteins in AGS cells from both the control and the TIIA treatment, the normalized peptide iTRAQ signal of each identified protein was summarized, to calculate protein ratios (TIIA treatment/ control).

\section{Western blot analysis}

AGS cells were treated with $5.3 \mu \mathrm{M}\left(\mathrm{IC}_{50}\right)$ TIIA or $0.1 \%$ DMSO control medium for $48 \mathrm{hr}$ after $24 \mathrm{hr}$ of seeding $\left(8 \times 10^{4}\right.$ cells/well in 6-well plates). Cells were harvested with trypsin/EDTA and total proteins were extracted. Then, proteins from control and TIIA-treated samples were separated in 12\% SDS-PAGE gels, and transferred onto $0.45 \mu \mathrm{m}$ PVDF membranes (Millipore) in a TransBlot ${ }^{\circ}$ SD Semi-Dry Transfer Cell (Bio-Rad) for $50 \mathrm{~min}$ at $400 \mathrm{~mA}$. The membrane was blocked for $1 \mathrm{hr}$ at room temperature in $5 \%$ non-fat milk powder/PBS-T $(1 \times$ PBS, $0.1 \%$ Tween 20 (Sigma-Aldrich)) and incubated overnight at $4^{\circ} \mathrm{C}$ with blocking buffer containing rabbit monoclonal antibodies to human RS2 (GeneTex; 1:1,000), PSMB3 (GeneTex; 1:1,000), phospho-CDK1 (Santa Cruz; 1:100), CDK1 (Santa Cruz; 1:100), Cyclin B1 (GeneTax; 1:500), Cdc25C (GeneTex; 1:1,000), G6PI (GeneTex; 1:1000), ENO1 (GeneTex; 1:2000), MDH1 (GeneTex; 1:500), PGK1 (GeneTex; 1:500), ALDOC (GeneTex; 1:250), PCK2 (GeneTex; 1:1000), LDH-B (GeneTex; 1:100), p53 (Santa Cruz; 1:500) or AKT (Santa Cruz; 1:1000). The membrane was washed with PBS-T, incubated $1 \mathrm{hr}$ with $5 \%$ non-fat milk 
powder/PBS-T containing anti-rabbit IgG antibodies $(1: 10,000)$ (Sigma-Aldrich) or anti-mouse IgG antibodies (SigmaAldrich, 1:10,000), washed and imaged with enhanced chemiluminescence (PerkinElmer). The membrane image was then analyzed by an AutoChemi Image System (UVP) or exposed to Fuji medical X-ray film, followed by quantification with AlphaView SA 3.4.0 (ProteinSimple).

\section{Intracellular ATP generation assay}

Cells were seeded onto 6 -well plates at $8 \times 10^{4}$ cells/well, and then incubated for $24 \mathrm{~h}$. For the control, 0.1\% DMSO was added to the medium, and for the treatment, $5.3 \mu \mathrm{M}$ TIIA was added. After $48 \mathrm{~h}$ of drug exposure, the medium was removed, and then cells were washed twice with PBS. The levels of intracellular ATP were determined using a bioluminescent somatic cell assay kit (Sigma-Aldrich), according to the manufacturer's instructions, and normalized to protein concentrations. Luminescence was detected using a FlexStation III (Molecular Devices). The ATP content of each sample was calculated as the average of the relative light readings and based on the ATP standard curve.

\section{Flow cytometry}

For cell cycle analysis, AGS cells were treated with TIIA or DMSO as control for $48 \mathrm{hr}$. TIIA treatment concentrations were $0.625 \mu \mathrm{M}, 1.25 \mu \mathrm{M}, 2.5 \mu \mathrm{M}$, and $5.3 \mu \mathrm{M}$; $0.1 \%$ DMSO dissolved in culture medium was used as control. After treatment, cells were harvested with trypsin/EDTA, fixed with $70 \%$ ethanol, then spun down, after which ethanol was removed. Then each sample was mixed with RNase A $(100 \mu \mathrm{g} / \mathrm{mL})$, incubated at $37^{\circ} \mathrm{C}$ for $1 \mathrm{hr}$, and stained with propidium iodide (PI) (Santa Cruz Biotechnology, Inc.) at a concentration of $100 \mu \mathrm{g} / \mathrm{mL}$ in the dark at room temperature for $15 \mathrm{~min}$. For apoptosis analysis, AGS cells were treated with TIIA or DMSO control medium for $48 \mathrm{hr}$ after $24 \mathrm{hr}$ of seeding $\left(3.5 \times 10^{5}\right.$ cells in 10-cm plates). TIIA treatment concentrations were $1.25 \mu \mathrm{M}$, and $5.3 \mu \mathrm{M} ; 0.1 \%$ DMSO dissolved in culture medium was used as control. After treatment, cells were harvested with trypsin/EDTA, suspended, and counted. Then each sample was adjusted to a concentration of $10^{6}$ cells/tube and stained with Annexin V-FITC (Santa Cruz Biotechnology, Inc.) and PI (Santa Cruz Biotechnology, Inc.) dissolved in binding buffer (Santa Cruz Biotechnology, Inc.) in the dark at room temperature for $15 \mathrm{~min}$. Both cell cycle distribution and apoptotic cells proportion were then analyzed with a BD FACSCanto II flow cytometer (BD Biosciences) and FCS Express 4 (BD Biosciences).

\section{Immunofluorescence staining}

AGS cells were treated with TIIA or DMSO control medium for $48 \mathrm{hr}$ after $24 \mathrm{hr}$ of seeding $\left(4 \times 10^{4}\right.$ cells in 6-well plates). TIIA treatment concentrations were $1.25 \mu \mathrm{M}$ and $5.3 \mu \mathrm{M}$, and $0.1 \%$ DMSO dissolved in culture medium was used as control. Cells were washed, fixed with $4 \%$ paraformaldehyde (Sigma-Aldrich) in PBS for $20 \mathrm{~min}$ at $37^{\circ} \mathrm{C}$, then permeabilized with $0.25 \%$ Triton X-100 (Sigma-Aldrich) in PBS for $10 \mathrm{~min}$ at room temperature. Then cells were incubated with 1\% BSA (Bioshop) in PBS as blocking buffer for $30 \mathrm{~min}$ at room temperature, and labeled with mouse monoclonal antibodies to human $\alpha$-tubulin (Millipore; 1:500) or $\gamma$-H2AX (Abcam; 1:500) dissolved in blocking buffer at $4^{\circ} \mathrm{C}$ overnight. After being washed with PBS three times, cells were labeled with antimouse FITC-IgG (Millipore; 1:100) and TRITC-conjugated Phalloidin (Millipore; 1:2000) dissolved in blocking buffer for $1 \mathrm{hr}$ in the dark at room temperature. Then cells were washed with PBS three times and mounted with ProLong ${ }^{\circ}$ Gold reagent with DAPI (Invitrogen). Images were acquired by using a fluorescence microscope with Leica HCX FL PLAN 1006/1.25 oil objective, a SPOT camera (Diagnostic Instruments), and were analyzed with SPOT Advanced software (Diagnostic Instruments).

\section{Statistical analysis}

Data were expressed as mean \pm standard deviation (SD) and analyzed using two-tailed Student's $t$-tests. In the cell proliferation assays, data were analyzed using the Wilcoxon Signed-Rank test. A P-value of less than 0.05 was taken to indicate statistical significance.

\section{Additional files}

Additional file 1: The scatter plot represents gene expression levels
(mRNA-RPKM) in the control and TIIA treatment samples. Colored
dots represent DEGS (FDR $\leq 0.001$ and $\mid \log _{2}($ fold-change) $\mid \geq 1$ ).
Additional file 2: List of RNA-seq identified genes and their expression
ratios (TIIA/Control).
Additional file 3: The top 50 enrichment functions of RNA-seq-
identified DEGs analyzed by MetaCore software.
Additional file 4: Detailed information on iTRAQ identified proteins
and peptide ratios (TIIA/Control).
Additional file 5: High reproducibility of iTRAQ-based proteomics
analysis. (A) Control sample peptides were equally divided into two
parts, C1 and C2, and labeled with iTRAQ 114 and 115 separately. The
distribution plot of iTRAQ ion intensity in control samples ( 711 peptides
identified) shows a high correlation ( ${ }^{2}=0.975$ ) between the two labels.
(B) Treatment (IC 50 dose of TIIA for 48 hr) sample peptides were equally
divided into two parts, T1 and T2, and labeled with iTRAQ 116 and 117
separately. The distribution plot of iTRAQ ion intensity in treatment
samples (711 peptides identified) shows a high correlation ( ${ }^{2}=0.984$ )
between the two labels.

\section{Competing interests}

The authors declare that they have no competing interests.

\section{Authors' contributions}

LLL and CRH designed and performed experiments. LLL, CRH, CLH, HCH and HFJ analyzed data. $\mathrm{HCH}$ and $\mathrm{HFJ}$ contributed reagents and guided all aspects of the project. LLL, CRH, HCH and HFJ co-wrote the paper. All authors read and approved the final manuscript. 


\section{Acknowledgements}

We acknowledged Technology Commons in College of Life Science, National Taiwan University for technical assistance with the Mascot search engine and flow cytometer. This work was supported by the National Science Council of Taiwan (NSC 102-2628-B-002-041-MY3, 102-2627-B-002-002, and 102-2311-B-010-004) and the National Taiwan University Cutting-Edge Steering Research Project (103R7602C3) and Translational Medicine Piloted Model Cooperation Projects of National Taiwan University Medical Campus and College of Life Science (103-L004)

\section{Author details}

'Department of Life Science, National Taiwan University, No. 1, Sec. 4, Roosevelt Road, Taipei 106, Taiwan. ${ }^{2}$ Institute of Biomedical Informatics and Center for Systems and Synthetic Biology, National Yang-Ming University, No.155, Sec.2, Linong Street, Taipei 112, Taiwan. ${ }^{3}$ Institute of Molecular and Cellular Biology, National Taiwan University, No. 1, Sec. 4, Roosevelt Road, Taipei 106, Taiwan. ${ }^{4}$ Graduate Institute of Biomedical Electronics and Bioinformatics, National Taiwan University, No. 1, Sec. 4, Roosevelt Road, Taipei 106, Taiwan.

\section{Received: 2 July 2014 Accepted: 9 January 2015}

\section{Published online: 05 February 2015}

\section{References}

1. Ferlay J, Shin HR, Bray F, Forman D, Mathers C, Parkin DM. Estimates of worldwide burden of cancer in 2008: GLOBOCAN 2008. Int J Cancer. 2010;127(12):2893-917.

2. Carden CP, Sarker D, Postel-Vinay S, Yap TA, Attard G, Banerji U, et al. Can molecular biomarker-based patient selection in phase I trials accelerate anticancer drug development? Drug Discov Today. 2010;15(3-4):88-97.

3. Lin R, Wang WR, Liu JT, Yang GD, Han CJ. Protective effect of tanshinone IIA on human umbilical vein endothelial cell injured by hydrogen peroxide and its mechanism. J Ethnopharmacol. 2006;108(2):217-22.

4. Chen J, Tina C. Chinese medical herbology and pharmacology. CA: Art of Medicine Press Inc; 2001

5. Ding M, Zhao GR, Yuan YJ, Guo ZX. Aqueous extract of Salvia miltiorrhoza regulates adhesion molecule expression of tumor necrosis factor alpha-induced endothelial cells by blocking activation of nuclear factor kappaB. J Cardiovasc Pharmacol. 2005;45(6):516-24.

6. Ren Y, Houghton PJ, Hider RC, Howes MJ. Novel diterpenoid acetylcholinesterase inhibitors from Salvia miltiorhiza. Planta Med. 2004;70(3):201-4.

7. Wasser S, Ho JM, Ang HK, Tan CE. Salvia miltiorrhiza reduces experimentallyinduced hepatic fibrosis in rats. J Hepatol. 1998;29(5):760-71.

8. Kim HH, Kim JH, Kwak HB, Huang H, Han SH, Ha H, et al. Inhibition of osteoclast differentiation and bone resorption by tanshinone IIA isolated from Salvia miltiorrhiza Bunge. Biochem Pharmacol. 2004;67(9):1647-56.

9. Tian G, Zhang Y, Zhang T, Yang F, Ito Y. Separation of tanshinones from Salvia miltiorrhiza Bunge by high-speed counter-current chromatography using stepwise elution. J Chromatogr A. 2000;904(1):107-11.

10. Wang X, Wei Y, Yuan S, Liu G, Lu Y, Zhang J, et al. Potential anticancer activity of tanshinone $\| \mathrm{A}$ against human breast cancer. Int J Cancer. 2005; 116(5):799-807.

11. Won SH, Lee HJ, Jeong SJ, Lu J, Kim SH. Activation of p53 signaling and inhibition of androgen receptor mediate tanshinone IIA induced G1 arrest in LNCaP prostate cancer cells. Phytother Res. 2012;26(5):669-74.

12. Shan YF, Shen X, Xie YK, Chen JC, Shi HQ, Yu ZP, et al. Inhibitory effects of tanshinone II-A on invasion and metastasis of human colon carcinoma cells. Acta Pharmacol Sin. 2009;30(11):1537-42.

13. Chiu TL, Su CC. Tanshinone IIA induces apoptosis in human lung cancer A549 cells through the induction of reactive oxygen species and decreasing the mitochondrial membrane potential. Int J Mol Med. 2010;25(2):231-6.

14. Liu J, Shen HM, Ong CN. Salvia miltiorrhiza inhibits cell growth and induces apoptosis in human hepatoma HepG(2) cells. Cancer Lett. 2000;153(1-2):85-93.

15. Yoon Y, Kim YO, Jeon WK, Park HJ, Sung HJ. Tanshinone IIA isolated from Salvia miltiorrhiza BUNGE induced apoptosis in HL60 human premyelocytic leukemia cell line. J Ethnopharmacol. 1999;68(1-3):121-7.

16. Chen J, Shi DY, Liu SL, Zhong L. Tanshinone IIA induces growth inhibition and apoptosis in gastric cancer in vitro and in vivo. Oncol Rep. 2012;27(2):523-8.
17. Munoz-Pinedo C, El Mjiyad N, Ricci JE. Cancer metabolism: current perspectives and future directions. Cell Death Dis. 2012;3:e248.

18. Gottlob K, Majewski N, Kennedy S, Kandel E, Robey RB, Hay N. Inhibition of early apoptotic events by Akt/PKB is dependent on the first committed step of glycolysis and mitochondrial hexokinase. Genes Dev. 2001;15(11):1406-18.

19. Metzker ML. Sequencing technologies - the next generation. Nat Rev Genet. 2010;11(1):31-46

20. Lin LL, Huang HC, Juan HF, for the Taida Cancer Systems Biology Study G. Deciphering molecular determinants of chemotherapy in gastrointestinal malignancy using systems biology approaches. Drug Discov Today. 2014;19(9):1402-9.

21. Wiese S, Reidegeld KA, Meyer HE, Warscheid B. Protein labeling by iTRAQ: a new tool for quantitative mass spectrometry in proteome research. Proteomics. 2007;7(3):340-50.

22. Wu WW, Wang G, Baek SJ, Shen RF. Comparative study of three proteomic quantitative methods, DIGE, CICAT, and iTRAQ, using 2D gel- or LC-MALDI TOF/TOF. J Proteome Res. 2006;5(3):651-8.

23. DeSouza L, Diehl G, Rodrigues MJ, Guo J, Romaschin AD, Colgan TJ, et al. Search for cancer markers from endometrial tissues using differentially labeled tags iTRAQ and CICAT with multidimensional liquid chromatography and tandem mass spectrometry. J Proteome Res. 2005;4(2):377-86.

24. Malumbres M, Barbacid M. Cell cycle, CDKs and cancer: a changing paradigm. Nat Rev Cancer. 2009;9(3):153-66.

25. Lapenna S, Giordano A. Cell cycle kinases as therapeutic targets for cancer. Nat Rev Drug Discov. 2009;8(7):547-66.

26. Chang HY, Shih MH, Huang HC, Tsai SR, Juan HF. Middle infrared radiation induces G2/M cell cycle arrest in A549 lung cancer cells. PLoS One. 2013:8:e54117.

27. Luo J, Su F, Chen D, Shiloh A, Gu W. Deacetylation of p53 modulates its effect on cell growth and apoptosis. Nature. 2000;408(6810):377-81.

28. Soldani C, Croce AC, Bottone MG, Fraschini A, Biggiogera M, Bottiroli G, et al. Apoptosis in tumour cells photosensitized with Rose Bengal acetate is induced by multiple organelle photodamage. Histochem Cell Biol. 2007;128(5):485-95.

29. Bottone M, Santin G, Aredia F, Bernocchi G, Pellicciari C. Morphologica features of organelles during apoptosis: an overview. Cells. 2013;2:294-305.

30. Moss DK, Betin VM, Malesinski SD, Lane JD. A novel role for microtubules in apoptotic chromatin dynamics and cellular fragmentation. J Cell Sci. 2006;119(Pt 11):2362-74.

31. Khanna KK, Jackson SP. DNA double-strand breaks: signaling, repair and the cancer connection. Nat Genet. 2001;27(3):247-54.

32. Rossi DJ, Bryder D, Seita J, Nussenzweig A, Hoeijmakers J, Weissman IL. Deficiencies in DNA damage repair limit the function of haematopoietic stem cells with age. Nature. 2007:447(7145):725-9.

33. Celeste A, Petersen S, Romanienko PJ, Fernandez-Capetillo O, Chen HT, Sedelnikova OA, et al. Genomic instability in mice lacking histone H2AX. Science. 2002;296(5569):922-7.

34. Podhorecka M, Skladanowski A, Bozko P. H2AX phosphorylation: its role in DNA damage response and cancer therapy. J Nucleic Acids. 2010;2010:920161.

35. Lin LL, Wang YH, Lai CY, Chau CL, Su GC, Yang CY, et al. Systems biology of meridians, acupoints, and chinese herbs in disease. Evid Based Complement Alternat Med. 2012;2012:372670.

36. Hironaka S, Zenda S, Boku N, Fukutomi A, Yoshino T, Onozawa Y. Weekly paclitaxel as second-line chemotherapy for advanced or recurrent gastric cancer. Gastric Cancer. 2006;9(1):14-8.

37. Pang H, Han B, Yu T, Peng Z. The complex regulation of tanshinone IIA in rats with hypertension-induced left ventricular hypertrophy. PLoS One. 2014;9(3):e92216

38. Tian HL, Yu T, Xu NN, Feng C, Zhou LY, Luo HW, et al. A novel compound modified from tanshinone inhibits tumor growth in vivo via activation of the intrinsic apoptotic pathway. Cancer Lett. 2010;297(1):18-30.

39. Won SH, Lee HJ, Jeong SJ, Lee HJ, Lee EO, Jung DB, et al. Tanshinone IIA induces mitochondria dependent apoptosis in prostate cancer cells in association with an inhibition of phosphoinositide 3-kinase/AKT pathway. Biol Pharm Bull. 2010;33(11):1828-34.

40. Liu JJ, Lin DJ, Liu PQ, Huang M, Li XD, Huang RW. Induction of apoptosis and inhibition of cell adhesive and invasive effects by tanshinone IIA in acute promyelocytic leukemia cells in vitro. J Biomed Sci. 2006;13(6):813-23. 
41. Dong X, Dong J, Peng G. Growth-inhibiting and apoptosis-inducing effects of tanshinone II A on human gastric carcinoma cells. J Huazhong Univ Sci Technolog Med Sci. 2007;27(6):706-9.

42. Altenberg B, Greulich KO. Genes of glycolysis are ubiquitously overexpressed in 24 cancer classes. Genomics. 2004;84(6):1014-20.

43. Gaitonde MK, Murray E, Cunningham VJ. Effect of 6-phosphogluconate on phosphoglucose isomerase in rat brain in vitro and in vivo. J Neurochem. 1989;52(5):1348-52.

44. Liotta LA, Mandler R, Murano G, Katz DA, Gordon RK, Chiang PK, et al. Tumor cell autocrine motility factor. Proc Natl Acad Sci U S A. 1986;83(10):3302-6.

45. Silletti $\mathrm{S}, \mathrm{Raz}$ A. Autocrine motility factor is a growth factor. Biochem Biophys Res Commun. 1993;194(1):446-57.

46. Funasaka $T$, Haga A, Raz A, Nagase $H$. Tumor autocrine motility factor induces hyperpermeability of endothelial and mesothelial cells leading to accumulation of ascites fluid. Biochem Biophys Res Commun. 2002;293(1):192-200.

47. Jiang WG, Raz A, Douglas-Jones A, Mansel RE. Expression of autocrine motility factor (AMF) and its receptor, AMFR, in human breast cancer. J Histochem Cytochem. 2006;54(2):231-41.

48. Haga A, Funasaka T, Niinaka Y, Raz A, Nagase H. Autocrine motility factor signaling induces tumor apoptotic resistance by regulations Apaf-1 and Caspase-9 apoptosome expression. Int J Cancer. 2003;107(5):707-14.

49. Feron O. Pyruvate into lactate and back: from the warburg effect to symbiotic energy fuel exchange in cancer cells. Radiother Oncol. 2009;92(3):329-33.

50. Zha $X$, Wang $F$, Wang $Y$, He $S$, Jing $Y$, Wu X, et al. Lactate dehydrogenase $B$ is critical for hyperactive mTOR-mediated tumorigenesis. Cancer Res. 2011;71(1):13-8

51. Dennison JB, Molina JR, Mitra S, Gonzalez-Angulo AM, Balko JM, Kuba MG, et al. Lactate dehydrogenase $B$ : a metabolic marker of response to neoadjuvant chemotherapy in breast cancer. Clin Cancer Res. 2013;19(13):3703-13.

52. McCleland ML, Adler AS, Shang Y, Hunsaker T, Truong T, Peterson D, et al. An integrated genomic screen identifies LDHB as an essential gene for triple-negative breast cancer. Cancer Res. 2012;72(22):5812-23.

53. Chen Y, Zhang H, Xu A, Li N, Liu J, Liu C, et al. Elevation of serum I-lactate dehydrogenase $\mathrm{B}$ correlated with the clinical stage of lung cancer. Lung Cancer. 2006;54(1):95-102.

54. Wan XB, Wei L, Li H, Dong M, Lin Q, Ma XK, et al. High pretreatment serum lactate dehydrogenase level correlates with disease relapse and predicts an inferior outcome in locally advanced nasopharyngeal carcinoma. Eur 」 Cancer. 2013;49(10):2356-64.

55. Bi X, Lin Q, Foo TW, Joshi S, You T, Shen HM, et al. Proteomic analysis of colorectal cancer reveals alterations in metabolic pathways: mechanism of tumorigenesis. Mol Cell Proteomics. 2006;5(6):1119-30.

56. Park JW, Kim SC, Kim WK, Hong JP, Kim KH, Yeo HY, et al. Expression of phosphoenolpyruvate carboxykinase linked to chemoradiation susceptibility of human colon cancer cells. BMC Cancer. 2014;14:160

57. Zhao S, Xu W, Jiang W, Yu W, Lin Y, Zhang T, et al. Regulation of cellular metabolism by protein lysine acetylation. Science. 2010;327(5968):1000-4.

58. Zieker D, Konigsrainer I, Traub F, Nieselt K, Knapp B, Schillinger C, et al. PGK1 a potential marker for peritoneal dissemination in gastric cancer. Cell Physiol Biochem. 2008;21(5-6):429-36.

59. Elstrom RL, Bauer DE, Buzzai M, Karnauskas R, Harris MH, Plas DR, et al. Akt stimulates aerobic glycolysis in cancer cells. Cancer Res. 2004:64(11):3892-9.

60. Loging WT, Reisman D. Elevated expression of ribosomal protein genes L37, RPP-1, and S2 in the presence of mutant p53. Cancer Epidemiol Biomarkers Prev. 1999;8(11):1011-6.

61. Yan MY, Chien SY, Kuo SJ, Chen DR, Su CC. Tanshinone IIA inhibits BT-20 human breast cancer cell proliferation through increasing caspase 12, GADD153 and phospho-p38 protein expression. Int J Mol Med. 2012;29(5):855-63.

62. Jacquemont $\mathrm{C}$, Taniguchi T. Proteasome function is required for DNA damage response and fanconi anemia pathway activation. Cancer Res. 2007;67(15):7395-405.

63. Yarden $\mathrm{Rl}$, Pardo-Reoyo $\mathrm{S}$, Sgagias $\mathrm{M}$, Cowan $\mathrm{KH}$, Brody LC. BRCA1 regulates the G2/M checkpoint by activating Chk1 kinase upon DNA damage. Nat Genet. 2002;30(3):285-9.

64. Elmore S. Apoptosis: a review of programmed cell death. Toxicol Pathol. 2007:35(4):495-516.
65. Grzanka A, Grzanka D, Orlikowska M. Cytoskeletal reorganization during process of apoptosis induced by cytostatic drugs in K-562 and HL-60 leukemia cell lines. Biochem Pharmacol. 2003;66(8):1611-7.

66. Li R, Yu C, Li Y, Lam TW, Yiu SM, Kristiansen K, et al. SOAP2: an improved ultrafast tool for short read alignment. Bioinformatics. 2009;25(15):1966-7.

67. Harrow J, Frankish A, Gonzalez JM, Tapanari E, Diekhans M, Kokocinski F, et al. GENCODE: the reference human genome annotation for the ENCODE project. Genome Res. 2012;22(9):1760-74.

68. Audic S, Claverie JM. The significance of digital gene expression profiles. Genome Res. 1997;7(10):986-95.

69. Han CL, Chien CW, Chen WC, Chen YR, Wu CP, Li H, et al. A multiplexed quantitative strategy for membrane proteomics: opportunities for mining therapeutic targets for autosomal dominant polycystic kidney disease. Mol Cell Proteomics. 2008;7(10):1983-97.

70. Vizcaino JA, Deutsch EW, Wang R, Csordas A, Reisinger F, Rios D, et al. ProteomeXchange provides globally coordinated proteomics data submission and dissemination. Nat Biotechnol. 2014;32(3):223-6.

71. Lin WT, Hung WN, Yian YH, Wu KP, Han CL, Chen YR, et al. Multi-Q: a fully automated tool for multiplexed protein quantitation. J Proteome Res. 2006;5(9):2328-38

72. Wu YH, Hu CW, Chien CW, Chen YJ, Huang HC, Juan HF. Quantitative proteomic analysis of human lung tumor xenografts treated with the ectopic ATP synthase inhibitor citreoviridin. PLoS One. 2013;8(8):e70642.

\section{Submit your next manuscript to BioMed Central and take full advantage of:}

- Convenient online submission

- Thorough peer review

- No space constraints or color figure charges

- Immediate publication on acceptance

- Inclusion in PubMed, CAS, Scopus and Google Scholar

- Research which is freely available for redistribution 